\title{
IMAges AND Kant's TheOry of Perception
}

\author{
SAMANTHA MATHERNE \\ University of California, Santa Cruz
}

\begin{abstract}
My aim in this paper is to offer a systematic analysis of a feature of Kant's theory of perception that tends to be overlooked, viz., his account of how the imagination forms images in perception. Although Kant emphasizes the centrality of this feature of perception, indeed, calling it a 'necessary ingredient' of perception, commentators have instead focused primarily on his account of sensibility and intuitions on the one hand, and understanding and concepts on the other. However, I show that careful attention to what he says about the nature of images, their connection to the imagination, and their role in perception in his Metaphysics Lectures, as well as in the Deduction and Schematism chapters of the first Critique reveals that Kant is working with a richer, more nuanced framework for perception than is often attributed to him. I contend that it is only once we have a revised framework for Kant's theory of perception in place that we will be able to make further headway in debates, e.g., about whether or not he is a conceptualist about perception.
\end{abstract}

\section{Introduction}

In the first edition of the Critique of Pure Reason, Kant makes the rather striking claim that, "the imagination is a necessary ingredient of perception itself" (A120 footnote). ${ }^{1}$ This statement appears in a footnote where he is criticizing empiricist ('psychological') approaches to perception:

1. References to Immanuel Kant's Critique of Pure Reason are to the section number and A and $B$ pagination of the first and second editions $(\mathbf{A} / \mathbf{B})$. All other references are to the section number, volume, and page of Kants gesammelte Schriften. Gr: Groundwork of the Metaphysics of Morals; KU: Critique of the Power of Judgment; Anthro: Anthropology from a Pragmatic Point of View; ML: Lectures on Metaphysics; DWL: Dohna-Wundlacken Logic, VL: Vienna Logic; JL: Jäsche Logic; FS: 'False Subtlety'; R: Notes and Fragments.

Contact: Samantha Matherne <smathern@ucsc.edu> 
No psychologist has yet thought that the imagination is a necessary ingredient of perception itself. This is so partly because ... it has been believed that the senses do not merely afford us impressions but also put them together, and produce images of objects, for which without doubt something more than the receptivity of impressions is required, namely a function of the synthesis of them. (A120 footnote, my emphasis)

One of the basic ideas that emerges in this passage is that Kant thinks the empiricist has gone wrong in explaining a particular feature of perception, viz., how a distinctive type of perceptual representation, an image [Bild], is produced. Whereas the empiricist maintains that images are produced by means of our receptive sensible capacities, Kant argues that 'something more' is required. He identifies this something more as the synthetic activity of the imagination: "There is thus an active faculty of the synthesis of the manifold [of sense] in us, which we call the imagination ... For the imagination is to bring the manifold of intuition into an image" (A120). What thus emerges in this context is Kant's commitment to the central role that the imagination and its activity of image formation play in perception. ${ }^{2}$

Yet in spite of the emphatic nature of Kant's claims here, in recent discussions of his philosophy of perception, this line of thought has not yet received due attention. It is my goal in this paper to begin remedying this lacuna by offering a systematic account of the role the imagination and image formation play in Kant's account of perception in both the pre-Critical and Critical periods.

However, before proceeding to the details of my interpretation, it is worth considering why these aspects of Kant's view tend to be overlooked. There are several variations of, and reasons for, this neglect. To begin, setting the topic of images aside, a number of commentators have not devoted any serious attention to Kant's account of the imagination's contribution to perception at all. ${ }^{3}$ I believe there are at least two motivations for this. In the first place, in contemporary

2. Given that Kant thinks the imagination and image formation are necessary ingredients of perception, he has a more narrow understanding of what perception involves than many contemporary theorists do (for a discussion of his narrow definition of perception [Wahrnehmung], see Tolley (2015). This being said, I believe his account of images bears directly on issues in contemporary philosophy of perception that concern the role that perspective plays in it. Here, I particularly have in mind what Noë (2004) calls the problem of "perceptual presence": given that perception is limited by our embodied perspective, how are we to explain our ability to perceive objects as having features that transcend that perspective, e.g., how can I perceive a house as having a back side even though I am looking at its front side or how can I perceive an apple as having a white core even though I am looking at its unbroken red surface. I return to this issue in my discussion of the phenomenological view of images in Section 3 below. press).

3. See, e.g., McDowell (1994; 2009), Engstrom (2006), Hanna (2011), Gomes (2014), McLear (in 
philosophy of mind, there is a tendency to distinguish between imaginative and perceptual activities: whereas the former, it seems, involves imagining something that is not and perhaps has never been present to us, e.g., in visualization or make-believe, perceiving appears to be quite different, depending on our interaction with what is present here and now. ${ }^{4}$ While this may tempt us to distance Kant's account of perception from his account of imagination, it is important to recognize that for thinkers in the early modern context, like Descartes and Berkeley, it was often supposed that the imagination was involved in the perceptual process, 5 in which case, we should not be surprised to find Kant proceed as he does, viz., by talking about the imagination in the context of perception. ${ }^{6}$

However, there is a second reason for the recent oversight of his account of imagination in perception, which stems from a trend internal to Kant scholarship: the imagination simply does not fit within the framework for perception that has come to dominate discussions of Kant's theory of perception, viz., the framework of 'sensibility and understanding' that was put forth by Wilfrid Sellars (in a certain mood) and popularized by John McDowell.7 Within this framework, Kant's account of perception is analyzed in terms of the relationship between two mental capacities, sensibility and understanding, and the distinctive type of representations each produces, intuitions and concepts. For commentators who focus exclusively on this framework, the contribution of a third imaginative capacity falls by the wayside. The problem with this strategy is that although Kant's analysis of sensibility and understanding is pivotal for his ac-

4. As Gendler makes this point, "To imagine something is to form a particular sort of mental representation of that thing. Imagining is typically distinguished from mental states such as perceiving, remembering and believing in that imagining $S$ does not require (that the subject consider) $S$ to be or have been the case, whereas the contrasting states do" (2013).

5. See, e.g., Descartes's claim in Treatise on Man that the retinal images required for perception depend on the surface of the pineal gland, which is the "seat of the imagination" (1972: 106) or Berkeley's analysis of the role imagination plays (by means of 'suggestion') in 'mediate' perception in Of the Principles of Human Knowledge and the Three Dialogues.

6. This is not to say that Kant thinks that the imagination is only exercised in perception; rather, he acknowledges that the imagination can also be exercised in mere imagining (see, e.g., Anthro 7:167-9, 174-6, 189-190; A201-2/B247, B275; ML 28:230-238, 28:585; R6315-6;). Indeed, both imagining and perceiving are operations that Kant traces back to the imagination as a basic faculty of the mind. He defines this faculty as "a faculty for representing an object even without its presence in intuition" and he allows for it to be exercised in different ways, e.g., in a priori and a posteriori ways and in productive and reproductive ways (B151; see also Anthro 7:167). Though these exercises all play an important role in Kant's theory of the imagination, for the purposes of this paper, my focus is on how the imagination functions in an a posteriori way in perception. For a discussion of Kant's more general theory of the imagination, see Matherne (2016).

7. See Sellars's Science and Metaphysics (1968) and McDowell's Mind and World (1994) and Having the World in View (2009). As I discuss below, however, in later work, Sellars (1978) addresses the role the imagination plays in Kant's theory of perception. 
count of perception, given that the imagination is also a persistent theme in his analysis, we cannot fully understand his view if we do not attend to the imagination's contribution.

To be sure, not all commentators have neglected Kant's account of the imagination in perception; nevertheless, few have concentrated on his analysis of the role images play in this process. ${ }^{8}$ This is perhaps due to another trend in contemporary discussions of the imagination, viz., the tendency to distance the imagination from images or mental imaging. As Amy Kind has pointed out, in spite of the long standing historical tradition to connect the imagination to images, Gilbert Ryle's imageless approach to the imagination in The Concept of Mind (1949) set the stage for how the imagination came to be analyzed in the second half of the $20^{\text {th }}$ century (Kind 2001: 85-6). Indeed, it is now more common to either distinguish imaginative activity from mental imaging or deny that the imagination is connected to images altogether. 9 So even if we are willing to acknowledge that Kant thinks the imagination is a necessary ingredient of perception, we might think (or, in some cases, explicitly argue) that this has nothing to do with a capacity for image formation. ${ }^{10}$ Yet given that this directly conflicts with the sorts of claims we see Kant make in the A120 footnote passage mentioned above, we have reason to worry that this approach does not do full justice to his views of perception either.

There is, however, a smaller set of commentators who have acknowledged that both the imagination and images play an important role in Kant's theory of perception; yet among these commentators, there is a tendency to focus exclusively on what Kant says about images in the Transcendental Deduction. ${ }^{11}$ While this is, no doubt, a crucial text, there are two other texts that make a vital

8. See, e.g., Young (1998), Allison (2001), Allais (2009), Land (2011), McLear (2015).

9. As examples of this, Kind (2001: 86) cites the imageless accounts of imagination defended by Shorter (1952), Armstrong (1968), and Dennett (1986), and the accounts that 'retreat' to the claim that imagining can occur without imaging defended by Scruton (1974), Walton (1990), and White (1990).

10. For some, the motivation for distinguishing imaging from Kant's account of perceiving stems from the distinction mentioned above: forming a mental image of an object seems very different from seeing an object. See, e.g., Strawson (1974: 54) and Young (1988: 142). In a slightly different vein, Sellars argues that imaging is different from imagining in perception because the latter requires conceptualization, while the former does not (1978: 236). Meanwhile other commentators argue that Kant cannot be defending an image-based account because he regards this as the empiricist (Humean) view, which he wants to offer an alternative to. Allison indicates that even if Kant mentions images, we need to refrain from interpreting Kant's imagination primarily as a capacity for mental imaging because failing to do so "brings [Kant's imagination] closer to familiar empiricist views that it actually is" (2004: 187). And Young argues that unlike Hume who thinks that the imagination is a capacity for forming images that play a causal role in 'occasioning' belief, Kant thinks that the imagination is capable of "grounding and justifying judgment," in which case Kant cannot be conceiving of the imagination as a capacity for mental imaging (1988: 140).

11. See, e.g., Rohs (2001), Wenzel (2005), Ginsborg (2008), Griffith (2012), and Williams (2012). 
contribution to our understanding of images in perception, which have received much less attention. The first text is Kant's Metaphysics $L_{1}$ Lectures from the 1770s, which includes his most sustained discussion of the nature of the representations involved in images. ${ }^{12}$ The second text is the Schematism chapter from the first Critique in which he augments his account of images from the Deduction in essential ways. ${ }^{13}$ Without taking these texts into account, our understanding of Kant's account of images in perception threatens to be incomplete. Insofar as these texts promise to shed light on the trajectory of his thought both from the pre-Critical to the Critical period and within the first Critique itself, in order to develop a full picture of Kant's analysis of images in perception, they need to be taken into account.

My aim in this paper is to begin filling in these gaps by offering an interpretation of Kant's theory of perception that turns on a systematic analysis of the role that the imagination and image formation plays in it. I hope to show that careful attention to what he says about the nature of images, their connection to the imagination, and their role in perception in the Metaphysics Lectures and the first Critique reveals that Kant is working with a richer, more nuanced framework for perception than is often attributed to him. I begin in Section 2 with a brief discussion of the framework of sensibility and understanding in which Kant's theory of perception is typically situated. In Section 3, however, I start building the case that we need to revise this framework to include what he says about images and the imagination by looking at the role images play in his account of perception in his Lectures on Metaphysics from the 1770s. In Section 4 I turn to his development of this theory of images in perception in the first Critique, specifically in his account of synthesis and image formation in the $\mathrm{A}$ and $\mathrm{B}$ versions of the Transcendental Deduction. Though the Deduction is crucial for understanding his theory of images, in Section 5 I argue that Kant does not complete his analysis of this issue until the Schematism chapter and it is for this reason that we should pay more attention to this chapter as making a central contribution to his account of perception. I conclude in Section 6 by

12. Makkreel (1990: Ch. 1) is among the few commentators who address these lectures; however, he does not then take up the topic of images in his analysis of the first Critique.

13. There are a few exceptions to this. Sellars's discussion of images turns on an analysis not of the Deduction, but of the Schematism; however, as he says his method is "not that of textual exegesis and commentary" (1978: 231). Longuenesse (1998) discusses the role images play in both the Deduction and the Schematism; however, she tends to focus not on the sorts of perceptual images I am concerned with here (she, e.g., mentions images as intuitive representations of perceptual objects only in passing on 208 and 272-3), but rather on the image of numbers (257-263) and space and time as the 'pure images' of magnitude (266-271). Paton (1936) also talks about images as they figure in the Deduction and Schematism and I will take up the differences between his interpretation and my own below. Meanwhile, Strawson (1974) touches on Kant's account of the imagination in the Deduction and the Schematism, yet his analysis of images tends to draw not on Kant's texts, but rather on a commonsensical understanding of images. 
exploring what implications this revised account of Kant's theory of perception might have for debates about whether or not he is a conceptualist. ${ }^{14}$ I suggest that if we include images in his framework for perception, then we shall find that he is a conceptualist, albeit a moderate one: on his view, whereas our ability to form images in perception is guided by concepts, this, in turn, depends on the non-conceptual deliveries of sensibility, i.e., intuition (in a narrow sense). ${ }^{15}$

\section{Perception within the Framework of Sensibility and Understanding}

Before proposing my revised framework for Kant's theory of perception, I want to begin by laying out the considerations in favor of situating his account of perception within the framework of sensibility and understanding. The tendency to read Kant's theory of perception in this light is encouraged by familiar passages such as the following:

Our cognition arises from two fundamental sources in the mind, the first of which is the reception of representations (the receptivity of impressions), the second the faculty for cognizing an object by means of these representations (spontaneity of concepts); through the former an object is given to us, through the latter it is thought in relation to that representation ... Intuition and concepts therefore constitute the elements of all our cognition (A50/B74).

Given that perception, for Kant, falls under the umbrella of cognition in some way, ${ }^{16}$ it is natural to take this passage, and others like it, to indicate that in order

14. 'Conceptualists' who argue that the intuitions involved in perception depend on concepts or conceptual capacities include McDowell (1994; 2009), Sedgwick (1997), Abela (2002: Chs. 23), Wenzel (2005), Engstrom (2006), Ginsborg (2008), Griffith (2012), Williams (2012), and Landy (2015: Ch. 3). 'Non-conceptualists' who argue that these intuitions do not involve concepts include Rohs (2001), Hanna (2005; 2008; 2011), Allais (2009), Grüne (2009; 2011), Tolley (2013), and McLear (2015).

15. I explain what I have in mind by intuitions in a narrow sense in Section 4.

16. I say 'in some way' because although in this passage Kant treats cognition as something that requires the coordination of concepts and intuitions, later in the Stufenleiter he says that either intuitions or concepts can count as cognitions $\left(\mathrm{A}_{320} / \mathrm{B}_{377}\right)$. While this is a vexed issue that I cannot do justice to here, taking our cue from the Stufenleiter I take his view to be that a cognition in the most general sense involves representations with consciousness that refer to an object (what he calls an "objective perception [Perzeption]," note the word he uses here is Perzeption and not Wahrnehmung, which he uses in the Deduction). There are, in turn, various species of cognition, including intuitions, concepts, 'experience' [Erfahrung] (which involves a combination of the two through the three-fold synthesis of apprehension, reproduction, and recognition), and 'perception' [Wahrnehmung] (which, I argue below, involves the formation of a distinctive type of representation, viz., 
to elucidate his account of perception, we must look to his analysis of the relationship between sensibility and intuitions, on the one hand, and understanding and concepts, on the other.

Kant, indeed, orients the first part of the first Critique, the 'Transcendental Doctrine of Elements', around an analysis of sensibility and understanding as the two 'elements' of cognition (A15/B29, $\left.\mathrm{A}_{21} / \mathrm{B}_{3} 6\right)$. In the first section, the 'Transcendental Aesthetic', Kant "first isolate[s] sensibility" (A22/B36) in order to study the nature of intuition, while in the second section, the "Transcendental Logic', he "isolate[s] the understanding . . . and elevate[s] from our cognition merely the part of our thought that has its origin solely in the understanding" (A62/B87). In the Aesthetic, Kant then characterizes sensibility as follows:

The capacity (receptivity) to acquire representations through the way in which we are affected by objects is called sensibility. Objects are therefore given to us by means of sensibility, and it alone affords us intuitions (A19/B33).

As we see here, Kant describes sensibility as a receptive capacity, which is responsible for giving us objects and he claims that 'it alone' is responsible for producing the sort of representation he calls an 'intuition'. He characterizes an empirical intuition as a representation that "is related to the object through sensation," where sensation is defined as a subjective representation that refers to our state insofar as we are affected by objects (A320/B377, see also A19-20/ B34). So whereas a sensation reflects a modification of our state, an intuition is a representation that reflects the object. More specifically, he argues that the objective representation involved in an intuition is a representation that "is immediately related to the object," i.e., it directly presents the object without having to go through any other representational intermediaries, and it is 'singular', i.e., a representation of a particular or an individual $\left(\mathrm{A}_{320} / \mathrm{B}_{377}\right.$, see also Aig/B33, A68/B93).

In contrast to the receptive nature of sensibility, Kant claims that the understanding is a spontaneous capacity by means of which we are able to think about the objects that are given to us through intuition $\left(\mathrm{A}_{51} / \mathrm{B}_{75}\right)$. And just as sensibility is responsible for intuitions, Kant maintains that the understanding is responsible for concepts: "Concepts are therefore grounded on the spontaneity of thinking, as sensible intuitions are grounded on the receptivity of impressions"

an image through the schema-guided synthesis of apprehension and reproduction that happens in accordance with a concept but does not require the synthesis of recognition). This point aside, given his different uses of 'cognition', both the conceptualist and the non-conceptualist could say that perception involves cognition if by 'cognition' the conceptualist has in mind the cognition involved in experience and the non-conceptualist has in mind the kind involved in intuition. 
(A68/B93). Unlike an intuition, Kant claims that a concept is the sort of representation that is 'mediately' related to an object "by means of a mark, which can be common to several things" (A320/B377, see also A68/B93). His idea is that a concept relates to an object through a generic representation of a property that can be instantiated by multiple objects. These conceptual representations serve as the intermediaries through which we are able to actively think about the objects provided to us by intuition.

It is within this framework of sensibility and understanding that Kant's account of perception is typically situated. For this reason, the analysis of his theory of perception has tended to turn on questions like, does Kant think that both sensibility and understanding are involved in perception and does Kant think that both intuitive and conceptual representations are required in order to perceive an object? ${ }^{17}$ This is why much of the recent literature on his account of perception has been concerned with how he conceives of intuitions and whether we can form perceptual representations that are immediately related to objects and are singular without relying on concepts (as the so-called 'non-conceptualists' would have it) or whether this depends on the possession of concepts or conceptual capacities (as the so-called 'conceptualists' would have it).

While these are no doubt important questions and ones that we shall return to in Section 6, in what follows, I show that any analysis of Kant's theory of perception solely within this framework of sensibility and understanding is incomplete because it neglects a key component of his account of perception, viz., the contribution of a third capacity, the imagination, and the distinctive representations, images, it contributes to perception. As we shall see, whether we look at Kant's early lectures, the Deduction, or the Schematism, the imagination and images play a central role in his account of perception, in which case, I argue we should revise our understanding of Kant's framework of perception accordingly.

\section{Images in the Metaphysics Lectures}

In order to begin restoring images and image formation to Kant's theory of perception, I want to begin my interpretation with an analysis of his view of images. ${ }^{18}$ As we shall soon see, Kant approaches images through a representational

17. For citations to the relevant secondary literature, see Section 1.

18. Given that Kant privileges the role images play in perception, his theory of perception belongs in a long tradition that treats visual perception as the paradigmatic case of perception. I think it would be possible to extend Kant's analysis of images to other sensory modalities if we de-emphasized his imagistic language and focused, instead, on his idea (discussed below) that perception involves holistic representations that represent an object from multiples sides and 
lens, ${ }^{19}$ so the question for us is what type of mental representation does Kant think images involve? ${ }^{20}$ Let's consider three different views of images we might attribute to Kant. ${ }^{21}$ According to one view, which we could label the imaginary

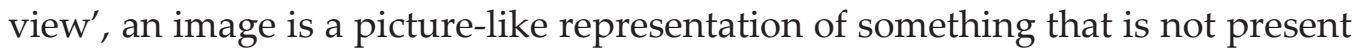
and perhaps has never been present. An example of this would be the image I form when I visualize myself finishing a marathon or picture what Anna Karenina looks like. Other accounts of images, however, make room for images to play a role in our current perceptions. On one such view, call it the 'snapshot view', images are treated like mental snapshots, i.e., as representations that capture a single spatio-temporal instance. When I, for example, look at the sun just as it dips below the horizon, we might think that I (much like my camera) form a representation of it that captures this precise moment. In a third more unorthodox vein, which I shall refer to as the 'phenomenological view', images can be regarded as complex, holistic representations that represent something from multiple spatio-temporal perspectives, e.g., an image of a house that represents not only the front-side that is directly given to me, but its back-side as well. ${ }^{22}$ Describing this view in a broadly Husserlian way, we could say an image is a holistic representation of multiple 'adumbrations' of a perceptual object, i.e., of the object as it appears from different perspectives. ${ }^{23}$ We could also cash out this

points of view. For while Kant focuses on the sides and points of view available to vision, we could broaden this view to includes those that are available to the other senses as well. To this end, one could perhaps draw on Kant's discussion in the Anthropology of the five senses (\$\$15-23), especially on touch and hearing, which he designates alongside sight as 'objective' senses, in contrast with taste and smell, which are 'subjective' (Anthro 7:157). This, however, is not a project I shall pursue here.

19. Insofar as Kant offers a representational analysis of images, his account should be distinguished from enactive accounts of images, which make imagery dependent not on representational states, but on our active, embodied engagement with the world (see, e.g., O'Regan and Noë 2001).

20. More specifically, I take Kant's view to be that images are representations of objects, i.e., they are the representational contents by means of which we are directed towards objects, and not internal represented objects (e.g., sense data) that we are directed towards in perception.

21. Given the textual evidence presented below, it seems clear that Kant conceives of images along pictorial lines, so in what follows I will not consider descriptionalist approaches to images, e.g., Dennett (1979).

22. Images in this sense can be understood as the sort of representations that are involved in the phenomena that Noë (2004) calls "perceptual presence," i.e., the phenomena in which we perceive an object as having features that are not, strictly speaking, present to us, e.g., when I perceive a house as having a back side even though I am looking at its front side. So understood, images are representations that represent not only the features of the object immediately present to us, but features of the object that are absent as well. For a discussion of how Kant's view bears on the problem of perceptual presence, see Sellars (1978), Thomas (2009), and Kind (in press).

23. Husserl describes adumbrations as follows: "A physical thing is necessarily given in mere "modes of appearance" in which necessarily a core of "what is actually presented" is apprehended as being surrounded by a horizon of "co-givenness". ... [The indeterminateness of the horizon] points ahead to possible perceptual multiplicities which, merging continuously into one another, join to- 
view of images in terms of what Sellars calls 'sense-image models'. ${ }^{24}$ On Sellars's view, a sense-image model is a representation that is, on the one hand, 'perspectival' or 'point-of-viewish' because it represents an object from our embodied point of view, and, on the other hand, it represents the "unified structure" of the object, i.e., the properties of the object that are both present and not present to us, e.g., the front-side, back-side, and inside of a red apple (Sellars 1978: 235-7). Unlike the imaginary view, then, the phenomenological view allows for images to represent the objects that are present to us in perception and unlike the snapshot view, it allows for images to represent perceptual objects from multiple perspectives. So which if any of these views of images would Kant endorse?

One of the most helpful places to look for Kant's answer to this question is his most extended discussion of the nature of images, which occurs in his Metaphysics $\mathrm{L}_{1}$ Lectures from the mid-1770s. Indeed, these lectures emerge as an invaluable resource because unlike in the first Critique where Kant has less to say directly about the representational content of images, he explicitly addresses this topic here. ${ }^{25}$ If we take our cue from these lectures, then it appears that Kant's analysis is in line with the phenomenological view. This is not to say that Kant denies that images can be produced in the way the imaginary view would have it. Indeed, in the Anthropology, he discusses how images play a role in fantasy

gether to make up the unity of one perception in which the continuously enduring physical thing is always showing some new "sides" (or else an old "side" as returning) in a new series of adumbrations" (1982: Section 44, 94). This being said, it is important to note that Husserl himself does not think that perception requires the mediation of an image (1982: Section 43), so my suggestion is only that we could draw on his account of adumbrations in order to flesh out a phenomenological view of images (even if it is not one Husserl would endorse).

24. I label Sellars's view a 'phenomenological' one because he offers his account of senseimage model as part of his "phenomenological reflection on the structure of perceptual experience" (1978: 231). Yet, to be clear, I am not suggesting that this is how Sellars himself treats images, for he draws a distinction between images, which represent a particular property of an object, and image models, which represent multiple properties of an object in a "unified image-structure" (1978: 236). There is a further complexity regarding the role of perspective on Sellars's view. On the one hand, he takes an image model to represent an object from our current embodied perspective; in which case, this perspectival aspect of the image model is restricted to our point of view at a particular moment in time. On the other hand, given that image models represent the properties of an object that are both present and non-present and that those non-present properties are available to other perspectives, we could also say that the image model represents the object from multiple perspectives. It is this latter feature of images, as representations of an object from multiple perspectives that I take to be at the core of the phenomenological view as I present it here.

25. This is not to say that he is silent about the representational content of images in the first Critique: his analysis of synthesis and schematism fills out his account from the Metaphysics Lectures in important ways, especially with respect to how such images are formed. However, the crucial insight into images as representations of objects from multiple sides and points of view is a distinctive contribution of the lectures and I believe it is what forms the basis of his account in the first Critique. 
and dreaming (Anthro 7:168). However, if we look at the Metaphysics Lectures, we find that his analysis of images is dominated by a discussion of the role they play in ordinary perception and this discussion falls in line with the phenomenological view. ${ }^{26}$

Let's begin our discussion of these lectures by considering the overall context in which Kant introduces the topic of images. ${ }^{27}$ His discussion of images is part of his broader analysis of the "sensible faculty of cognition," which he claims is the faculty responsible for "representations that we have of objects so far as we are affected by them" (ML 28:230). ${ }^{28} \mathrm{He}$, in turn, delineates sensible representations into two categories: those that are 'given' and those that are 'made', which I shall refer to as 'given-representations' and 'made-representations', respectively (ML 28:230). The given-representations or what Kant calls "representations of the senses themselves" arise passively in us when we are affected by objects (ML 28:230). ${ }^{29}$ Meanwhile, he describes a made-representation as an "imitated representations of the senses," i.e., a representation of the given-representations of the senses (ML 28:230). Kant claims that unlike given-representations, which arise passively through the senses, made-representations require that we do something, that we make them in some sense. As he puts it, made-representations "arise from the spontaneity of the mind" and he identifies something he labels the 'formative power' [bildende Kraft] as the mental capacity responsible for these representations ( $\mathrm{ML}$ 28:230). This formative power is what he will later call the 'imagination' [Einbildungskraft] in the first Critique, so for the sake of continuity, I will refer to the 'formative power' as the 'imagination' in what follows. ${ }^{30}$

26. Moreover, as we shall see in the following section, it is this perceptual sense of images that he picks up on in the first Critique.

27. See Makkreel (1990: Ch.1) for an extensive discussion of these lectures.

28. The sensible or 'lower' faculty of cognition contrasts with what Kant calls the 'higher faculty of cognition' and 'understanding', which is responsible for judgment and "the representations which we have through voluntary practice, where we are the author of the representations" (ML 28:238). As we shall see below, although in these lectures Kant appears to treat the imagination as something that falls under the umbrella of sensibility, by the time he writes the A version of the first Critique, he comes to conceive of the imagination as something that occupies an intermediary position between sensibility and understanding. I return to this, as well as the complications surrounding the relationship between the imagination and understanding in the B Deduction in Section 4 .

29. Given-representations as he conceives of them in these lectures encompass what he in the first Critique defines as sensations (representations of the subject insofar as she is affected by the object), intuitions (representations of the object that affects us), and the representations of the parts of an object that go to make up the manifold of intuition.

30. In these lectures, Kant characterizes the imagination in a narrow sense, viz., as the "faculty for producing images from oneself, independent of the actuality of objects, where the images are not borrowed from experience. E.g., an architect pretends to build a house which he has not yet seen," and Kant treats it as a subsidiary of the much more expansive capacity that he calls the "for- 
According to Kant, the imagination is capable of forming a wide variety of made-representations. To be sure, he thinks that the imagination can produce representations involved in fiction or make-believe, e.g., imagining a piece of cake in front of me right now (ML 28:237). However, he does not restrict imaginative activity to this imaginary realm; he argues that the imagination is also involved in more mundane activities, like remembering the past, anticipating the future, and perceiving the world around us (ML 28:235). In memory, Kant suggests that the imagination operates as a "faculty of imitation" [Vermögen der Nachbildung] and forms or 'imitates' representations of objects we have encountered in the past, e.g., when I form a representation of my last birthday cake (ML 28:235). Meanwhile Kant claims that the imagination can also operate as a "faculty of anticipation" [Vermögen der Vorbildung] and can project representations into the future, e.g., if I imagine what next year's birthday cake will look like (ML 28:235). Finally, and here is where his account of images differs from the imaginary view discussed above, he maintains that the imagination is also involved in our current sense perceptions, helping us form representations of objects that are present to us, e.g., of the piece of cake on my plate right now. Kant characterizes the imagination as it operates in perception as a "faculty of illustration" [Vermögen der Abbildung] and he identifies the representations it forms as 'images' [Bilder] (ML 28:235). $3^{1}$

Having set the imaginary view aside, I want to now consider why his further comments about images signal the phenomenological, rather than the snapshot view. In one of his more lengthy descriptions of how the mind "forms an image of the object," he says,

mative power', which is a spontaneous capacity that produces a broad range of representations, e.g., in perception, in memory, and in anticipation (ML 28:237). This being said, in the $\mathrm{L}_{1}$ Lectures there appears to be some tension in how Kant presents the formative power: whereas at the outset he presents it under the heading of sensibility, later he claims that it is a power that "is between understanding and sensibility" (ML 28:239). Indeed, he then goes on to claim that, "If this formative power is in the abstract <in abstracto>, then it is the understanding" (ML 28:239). The tension in his view is perhaps generated by his description of the formative power as 'spontaneous' since this sits uneasily with both his description of sensibility as a passive capacity and his description of the understanding as a 'voluntary' capacity, that unlike sensibility does not form representations because it is "affected by" objects, but instead because it is the "author of representations" (ML 28:238). Indeed, as Goy points out in her detailed analysis of Kant's use of the term 'formative power' throughout his corpus, after 1780 he stops using 'formative power' as an epistemological term and uses it as a biological term instead (2012: Section 1.1). Thus in the first Critique, we find him attributing activities that belonged to the formative power in the $\mathrm{L}_{1}$ Lectures to a more expansively defined imagination. We also find him abandon the claim that the formative power is subsumed under sensibility and focus, instead, on the idea that it is capable of mediating between sensibility and understanding (this at least is his view in the A edition; we will return to issues surrounding whether in the $\mathrm{B}$ edition he subsumes the imagination under the understanding below).

31. See Makkreel (1990: 15-19) for a discussion of image formation in these lectures. 
The mind must undertake many observations in order to illustrate [abzubilden] an object differently from each side. ... There are thus many appearances of a matter according to the various sides and points of view. The mind must make an illustration [Abbildung] from all these appearances by taking them all together. (ML 28:236)

Notice that Kant's images do not, as the snapshot view would have it, just capture a single appearance of an object from one side or one point of view; instead, much more in the spirit of the phenomenological view, his images bring 'all these appearances' together in a holistic 'illustration' of the object from 'various sides and points of view'. ${ }^{32}$ To clarify his view, Kant picks the example of forming an image of a city. He says that when we visit a city, "the mind then forms an image of the object which it has before it while it runs through the manifold" (ML 28:235). By a 'manifold', Kant has in mind the multiple given-representations that represent the city from different sides and points of view. He claims that this manifold is the result of the mind "undertak[ing] many observations. . . . E.g., a city appears different from the east than from the west" (ML 28:236). If, for example, I am wandering around Paris, a host of given-representations will arise in me, as I observe Paris from atop the Eiffel tower, along the Seine, at Sacré Coeur, etc., and these representations together constitute the manifold that Kant is talking about. According to Kant, in order to form an image or 'illustration' of Paris on the basis of this manifold my imagination needs to 'run through' the representations in the manifold and 'take them all together'. The resulting image would be a complex, holistic representation of Paris, which represents it from various sides and points of view.

Though image formation can occur on a large scale as in the Paris example, insofar as Kant takes images to be involved in perception more generally this process should occur in our perception of smaller objects as well. If, for example, I am at a cocktail party, my senses might produce different given-representations of a particular champagne flute, e.g., as I notice its glint, curviness, how it looks across the room, how it looks in my hand, etc. On Kant's view, in order to form an image of this smaller object, my imagination must run through the manifold of these given-representations and combine them together in an illustration of the flute from different sides and points of view. 33

32. Sellars also emphasizes the role perspective plays in imaginative activity in a Kantian account of perception (1978: Part III); however, see footnote 24 above for a discussion of the different roles perspective plays on his account.

33. Although in both of these cases, the perception of the object is extended over a longer period of time, even if our encounter with an object is very brief, we still form representations of the object that reflect smaller-scale shifts in perspective, including how our eyes scan our perceptual field, how our eyes focus on objects in that field, and how our bodily position shifts during this time. So even if I quickly look at an object and never see it again, I could still be in a position to 
Ultimately, what these lectures indicate is not only that images and image formation play an important role in Kant's framework for perception, but also that he endorses a phenomenological view of images, according to which an image is what is actively produced by the imagination when it runs through a manifold of given-representations and combines them together into a more complex, holistic made-representation, which illustrates a perceptual object from different sides and points of view. Although this phenomenological model of images is the one that emerges in the pre-Critical period, in the next section I argue that Kant preserves this basic approach to images and their centrality to perception, although he refines it in important ways, especially with respect to his analysis of the imaginative activity required in order to produce images. ${ }^{34}$

\section{Images in the Transcendental Deduction}

Let's turn now to the first Critique and begin by considering the role that images play in the framework for perception that Kant employs in the Transcendental Deduction. What I would like to suggest is that in the Deduction, Kant follows a pattern similar to that of the Metaphysics Lectures insofar as he draws a distinction between intuitions defined in a narrow sense as representations that are afforded to us through the receptivity of sensibility alone and images defined as the more complex sensible representations that are formed on the basis of intuitions. Moreover, I show that, just as in the lectures, Kant claims that in order for perception to occur, it is not enough for sensibility to provide us with intuitions; we need the imagination to produce images.

form an image of it if I combined together the representations of it from those smaller-scale perspectives into an image.

34. To be clear, I do not mean to imply that in the Critical period Kant takes over the view from the Metaphysics Lectures wholesale. Indeed, in addition to shifting away from an analysis of the formative power towards a more expanded analysis of the imagination (see footnote 30 above), in the Critical period, Kant makes a significant advance concerning the role of the transcendental synthesis of the imagination. Whereas in the Metaphysics Lectures he focuses on the empirical synthesis required for perception (through what he in the first Critique calls the 'reproductive imagination'), in both versions of the Transcendental Deduction he develops a robust account of the a priori synthesis of the 'productive imagination', which makes the empirical synthesis possible in the first place. However, given the constraints of this paper I shall focus primarily on the empirical synthesis of the imagination and the role it plays in image formation in perception. This means I will also leave aside a discussion of the a posteriori exercises of the productive imagination, e.g., in judgments of taste (KU 5:240); genius (KU 5:314); and in its 'fictive'/'inventive' [dichtend] activities, like fantasying and dreaming (ML 29:885-7; Anthro: Sections 28, 31). 


\subsection{Intuitions versus Images}

To begin, although Kant at times uses 'intuition' in a broad sense to refer to any sensible representation, whether produced through sensibility or imagination, 35 there is a more narrow use of 'intuition' that he employs in the Transcendental Aesthetic and Transcendental Logic to designate representations that are produced through sensibility qua our receptive capacity alone. ${ }^{36}$ As we have already seen, Kant claims that sensibility "alone affords us intuitions" and this is what he focuses on in the Aesthetic (A19/B33, my emphasis). Then, when he proceeds with the Logic, he appears to take it for granted that he has already dealt with the origin of intuitions in sensibility and is now moving on to a new topic, viz., how those already given intuitions are taken up and processed by our imagination and understanding. Kant's technical term for this processing is 'synthesis' and although we will return to this issue at length below, for now what I want to emphasize is Kant's idea in the Logic that synthesis is an activity that goes to work, as it were, on intuitions that sensibility has proffered. In the A Deduction, for example, he claims that there are "three original sources" of experience:

1) the synopsis of the manifold [of intuition] a priori through sense, 2) the synthesis of this manifold through the imagination; finally 3) the unity of this synthesis through original apperception. ... We have discussed this with regard to the senses in the first part above [i.e., the Aesthetic], however, we will now attempt to understand the nature of the two other ones. (A94-5)

As this passage indicates, by this point in the first Critique he assumes that he has already explained the 'synopsis' of sense, by means of which "it contains

35. See, e.g., Anthro (7:153, 167) and DWL (16: 701-2, 705) where Kant defines sense as the 'faculty of intuition in the presence of an object' and imagination as the 'faculty of intuition without the presence of an object'. Intuitions in a broad sense thus encompass intuitions in the narrow sense, as well the sort of representations Kant attributes to the imagination, including images and schemata.

36. This latter claim is in tension with a recent trend among commentators who argue that the intuitions Kant is concerned with in the Aesthetic are dependent in some sense upon the sorts of synthesis Kant describes in the Deduction. While I shall return to this issue in Section 6, this claim has been defended by conceptualists and non-conceptualists alike: conceptualists like Sellars (1968) and McDowell (1994; 2009) have argued that intuitions depend on the sort of concepts and conceptual capacities that are at issue in the Deduction; non-conceptualists like Hanna (2005: 249,267 ) and Allais (2009 394-5) argue that intuitions depend on the imaginative synthesis of apprehension and reproduction, though not on the conceptual synthesis of recognition; and finally Grüne (2009: Ch. 3) and Landy (2015: Ch. 3) have argued that intuitions depend on the synthesis of apprehension, reproduction, and recognition. For recent arguments in support of view that intuition can have its own unity prior to synthesis, see Tolley (2013), McLear (2015), Allais (2015). 
a manifold in its intuition" and it is the synthesis of this intuitive manifold by the imagination and the unity of that synthesis through apperception that will concern him in the Deduction (A97). ${ }^{37}$ In a similar vein in the B Deduction, Kant opens $\S 15$ with the claim that,

The manifold of representations can be given in an intuition that is merely sensible, i.e., nothing but receptivity .... Yet the combination (conjunctio) of a manifold in general can never come to us through the senses.... for it is an act of the spontaneity of the power of representation. (B129, my emphasis)

In this passage, Kant takes the manifold of intuition to be something that is given through receptivity, i.e., sensibility alone, and takes the topic of the combination of that manifold through spontaneous acts of synthesis to be the subject of the Deduction. Both versions of the Deduction thus appear to be in line with Kant's thought from the Metaphysics Lectures that while sensibility qua our receptive capacity affords us representations, i.e., intuitions containing a manifold, there are further spontaneous acts we engage in through which we process that manifold.

In contrast to intuition in this narrow sense, images do not become an integral part of Kant's account in the first Critique until his discussion of synthesis in the Deduction. And in this context he reiterates the idea from the Metaphysics Lectures that images are a distinctive type of complex, holistic sensible representation, which are produced by the imagination on the basis of what is given through the senses and that these images are required for perception. He states this most explicitly in the portion of the A Deduction that we considered at the outset of this paper. Recall he claims that, "There is thus an active faculty of the synthesis of the manifold in us, which we call imagination. ... For the imagination is to bring the manifold of intuition into an image" (A120). Again, he stresses this point because he thinks that it is precisely on this issue that other empiricist accounts of perception have gone wrong (and here is the quote we began with):

No psychologist has yet thought that the imagination is a necessary ingredient of perception itself. This is partly because ... it has been believed that the senses do not merely afford us impressions but also put them together, and produce images of objects, for which without doubt

37. Although Kant's mention here of the synopsis of sense is quite suggestive, he only alludes to this idea twice in the A Deduction, in the above-cited passage and at A97, and on neither occasion does he elaborate on what he means. Perhaps it drops out of the B Deduction because he conceives of it as part of the 'subjective deduction' and as such it is not as central to the 'objective deduction', which is his primary concern there (Axvi-xvii). 
something more than the receptivity of impressions is required, namely a function of the synthesis of them. (A120 footnote) $)^{38}$

This passage is significant because Kant makes it clear that perception requires something more than being sensibly receptive, i.e., more than the intuitions that are afforded to us through sensibility alone; it requires that the imagination engages in acts of synthesis in which it 'puts together' those intuitive representations and 'produces images' on this basis. ${ }^{39}$ Kant makes a similar point in the B Deduction with his example of perceiving a house: "I make the empirical intuition of a house into a perception through apprehension of its manifold ... and I as it were draw its shape [zeichne gleichsam seine Gestalt]" (B162, my emphasis).40 While I will return to this passage in more detail below, for now, I want to point out that Kant is once again drawing a distinction between intuiting a house and perceiving a house: for the latter to occur I must 'draw', i.e., form an image of the house's shape through apprehension, which is a form of synthesis that can be ascribed to the imagination. $4^{11}$ At least implicitly, what Kant appears to have

38. This passage indicates, pace Allison (2004: 187), that Kant's issue with the empiricists is not that they think perception involves images, but rather the way in which they account for image formation.

39. There is admittedly some tension in Kant's use of the term 'perception'. In the A120-1 passage, for example, he describes perceptions, on the one hand, as constituents of the manifold ("since every appearance contains a manifold, thus different perceptions by themselves are encountered dispersed and separate in the mind ..."), and, on the other hand, as the product of the imagination synthesizing the manifold into an image (it is a "necessary ingredient of perception" that the imagination "put [impressions] together, and produces images of objects"). However, when Kant is at his most technical, it appears that he endorses the latter as his considered view of perception. Consider, for example, in the B Deduction where he claims that, "by the synthesis of apprehension I understand the composition of the manifold in an empirical intuition, through which perception, i.e., empirical consciousness of it (as appearance), becomes possible" (B160). Reiterating this conception of perception on the next page, he says, that we "make the empirical intuition of a house into perception through apprehension of its manifold ... and I as it were draw its shape" (B162). In these passages in the B Deduction, he defines a perception not as a representation contained in the manifold of intuition, but rather as the specific type of cognition (for this use of 'cognition', see footnote 16 above) that results when that manifold is imaginatively synthesized into an image. This seems to be the picture of perception that he begins with at the outset of the Ar2o passage, claiming that, "The first thing that is given to us is appearance, which, if it is combined with consciousness, is called perception," and it is the one he expresses in the necessary ingredient footnote. For these reasons, I think we can attribute to Kant a technical view of perception as a specific type of cognition that requires imaginative synthesis and image formation. See Tolley $(2013$ : Section 6.3; 2015) for more discussion of the distinction Kant draws between intuition and perception.

40. Although Kant does not use the term 'image' in this passage, it seems implicit in the idea that we 'draw' the house's shape, and insofar as he treats this as the outcome of the synthesis of apprehension, even though he does not discuss images directly in the B Deduction, they seem implicated in his account of apprehension, which is a central topic.

41. We will return in more detail below both to the topic of apprehension and to Kant's apparent claims in the B Deduction that all synthesis, even apprehension, is an exercise of the under- 
in mind in this example is the idea familiar from both the Metaphysics Lectures and the A Deduction that in order to perceive something, we must not just intuit it, but engage in a synthetic act through which we form an image of it. For Kant, then, perception requires more than us having intuitions in the narrow sense; it requires images..$^{2}$

Now we may wonder why Kant thinks that perception requires images over and above the intuitions afforded by sensibility. After all, Kant claims that an intuition is a singular representation that is immediately related to an object and that the manifold of intuition is connected together by means of 'synopsis'. Though this might suggest that intuitions in the narrow sense are enough for perception, Kant also asserts that prior to synthesis the representations within the manifold are "dispersed and separate in the mind" and that "a combination of them, which they cannot have in sense itself, is therefore necessary" (A120, my emphasis). ${ }^{43}$ He then immediately proceeds to make the now familiar claim that the imagination is a "faculty of the synthesis of this manifold in us" and that it engages in synthesis "in order to bring the manifold of intuition into an image" (A120). And it is in this context that he inserts the footnote about the imagination being a necessary ingredient in perception. So why does he think that intuition in the narrow sense and the synopsis that pertains to it are not enough for perception?

Kant says little about the nature of synopsis, claiming only that the synopsis of the manifold is 'grounded' on sense and that he "ascribe[s] a synopsis to sense, because it contains a manifold in its intuition" (A94, A97). From these two passages, however, we can glean the idea that synopsis is something that happens through sensibility and it is by means of it that an intuition comes to 'contain' a manifold. As I understand the manifold of intuition in this context, it is not a manifold of sensations, i.e., subjective representations that reflect how an object affects us, but rather a manifold of objective representations that reflect the vari-

standing not the imagination per se.

42. I take Kant's claim here to be quite strong: image formation is necessary for perception in such a way that if we are not able to form an image of an object, although we might be able to intuit it, we cannot, strictly speaking, perceive it. So, for example, in both the Metaphysics Lectures and in the third Critique, Kant offers the example of visiting St. Peter's in Rome for the first time and being so overwhelmed by its "manifold splendor" that the imagination cannot "go through the manifold in order to illustrate it" (or in his language from the third Critique, "present the ideas of a whole") (ML 28:236; KU 5:252). Given that the person here cannot form an image of St. Peter's, Kant's position is that she does not strictly speaking perceive St. Peter's. To be sure, she is forming an intuition of St. Peter's that contains a manifold; however, given that Kant requires images be involved in perception, he would characterize this not as a perception, but rather as an intuition of St. Peter's. If, however, we form images in accordance with the sort of synthesis that he describes in the Deduction and Schematism, then we can be said to perceive an object.

43. See footnote 39 above for my discussion of the fact that Kant says it is 'perceptions' that are encountered as dispersed and separate in the mind. 
ous parts of the object. ${ }^{44}$ To use his example of a house, the manifold of intuition for a house includes the representations of its various parts, e.g., its roof, its windows, its front door, its back façade, etc. (A191-2/B236-7). ${ }^{45}$ For Kant, then, a manifold is not something that has to reflect a single spatio-temporal instance, but rather it can reflect multiple spatio-temporal instances. But why should we think that the representations that are contained in this sort of manifold of intuition are still dispersed and separate in the mind?

Section I in the A Deduction offers us crucial insight into Kant's answer. ${ }^{46} \mathrm{He}$ asserts that although "every intuition contains a manifold in itself," in order for that manifold to be represented "as such,"

it is necessary first to run through and then to take together this manifoldness, which action I call the synthesis of apprehension, since it is aimed directly at the intuition, which to be sure provides a manifold but can never effect this as such, and indeed as contained in one representation, without the occurrence of such a synthesis. (A99)

Though I will have more to say about apprehension below, what is relevant here is that Kant thinks that we can represent a manifold 'as such' or as 'one representation' only if we 'run through and take together' the manifold in synthesis. I take Kant's idea to be that although through synopsis the manifold comes to contain representations of various aspects of the object, e.g., its front- and back side, these representations are still dispersed and separate because we have not yet represented the manifold in a holistic way, as something that contains representations of an object from multiple sides and points of view. However, when we represent the manifold 'as such' or as 'one representation', we form a holistic representation in which we combine the various representations within the manifold together as representations of parts of a whole. It is only once this happens that the representations in the manifold cease to be separate and dispersed in the mind. For example, suppose I watch a waiter carry a champagne flute to my table. I will form representations of the various aspects of the flute, e.g., of its

44. Although Kant does suggest that a sensation "is contained" in an intuition (A50/B 74$)$, I think we can distinguish between what is contained in an intuition and what is contained in the manifold. Whereas the latter only contains objective representations, the former contains both objective and subjective representations, i.e., sensations. On my interpretation, then, though an intuition contains a manifold, it is not exhausted by it because it also contains sensations.

45. See also his description of the manifold of a country house in JL (9:34). I also take this to be the sort of conception of the manifold he has in mind in the above-mentioned example of the manifold of a city in the Metaphysics Lectures (ML 28:236).

46. See Tolley (2013: Section 6.1) for a discussion of this section with particular emphasis on the idea that Kant draws a distinction between an intuition containing a manifold and being represented as containing a manifold through synthesis. 
curviness, glint, transparency, etc., and through synopsis these representations will be contained in a manifold of intuition. Yet, on Kant's view, although these representations fill up the manifold, they will remain separate and dispersed in the manifold until I synthesize them together into a more holistic representation of the flute from multiple sides and points of view.

For Kant, then, it is not through synopsis, but through synthesis that we arrive at holistic representations of objects from multiple sides and points of view. And given that these sorts of holistic representations are what he identifies as images 47 and that he takes them to be a necessary ingredient of perception, on Kant's view, perception requires images over and above intuitions in the narrow sense.

\subsection{Image Formation and Synthesis}

While the preceding analysis reveals that images play an important role in Kant's framework for perception in the Deduction, matters become much more complicated when we try and tease out just what sorts of synthetic acts are involved in image formation. In the Metaphysical Deduction, Kant defines synthesis in a seemingly straightforward way: "By synthesis in the most general sense, however, I understand the action of putting different representations together with each other," and he claims that through synthesis, the manifold of intuition is "gone through, taken up, and combined" [durchgegangen, aufgenommen und verbunden] (A77/B103). However, in the Transcendental Deduction Kant's account of synthesis becomes much more thorny. For one thing, in the A Deduction he focuses on the so-called 'threefold' synthesis of apprehension, reproduction, and recognition, attributing apprehension and reproduction to the imagination and recognition to the understanding (A97). Meanwhile in the B Deduction, Kant appears to claim that all synthesis is ultimately an "action of the understanding" and that whatever we might ascribe to the imagination, in fact, has its seat in the understanding (B130). So where does image formation in perception fit into this more complex picture? ${ }^{4}$

Let's begin with the relationship between images and synthesis as it figures in the A Deduction. Setting aside the synthesis of recognition for the moment, on Kant's view apprehension and reproduction are two different, but "inseparably combined" types of synthesis that are jointly responsible for our being able to

47. As we might make the point about images in this context, when we represent a manifold 'as such', we represent it as an 'illustration' of an object from multiple sides and points of view, and this requires not just that the partial representations be contained in the manifold, but that we 'draw' all the parts together in synthesis.

48. Once again, to give a complete analysis of these forms of imaginative synthesis, we would need to also take into consideration the transcendental synthesis of the imagination upon which they rest; however, this is a topic I have had to set aside for this paper. 
produce the images required for perception (A102). He makes this clear in the context of the now familiar A120 passage, which I shall quote at length:

There is thus an active faculty of the synthesis of this manifold in us, which we call imagination. ... For the imagination to bring the manifold into an image; it must therefore ... apprehend [impressions]. It is, however, clear that even this apprehension of the manifold alone would bring forth no image ... were there not... a reproductive faculty of the imagination. (A120-1)

As he sometimes makes this point, apprehension and reproduction must work together in order to form a "whole representation" [eine ganze Vorstellung] on the basis of the manifold, i.e., a representation that combines together the partial and perspectival representations present in the manifold of intuition (A99).49

Taking a closer look at apprehension, Kant claims that in order to "bring the manifold of intuition into an image ... [the imagination must] antecedently take up the impressions into its activity, i.e., apprehend them" (A120)..$^{0}$ The act of apprehending, on Kant's view, involves "run[ning] through the manifold

49. As Kant cashes out this imaginative synthesis in the third Critique, the imagination can engage in two activities: "apprehension [Auffassung] (apprehensio) and comprehension [Zusammenfassung] (comprehensio aesthetica)" (KU 5:251). He claims that it is the job of apprehension to successively gather together the representations of the various parts of an object (KU 5:252). Meanwhile, it is the job of comprehension to combine these representations together into a single "intuition of the imagination," which represents the object as a "whole' (KU 5:254) (I take it that he is using 'intuition' in the broad sense here). He argues that in order for comprehension to be effective, the representations we have apprehended cannot "fade in the imagination," rather we must be able to hold on to them in order to produce the requisite holistic representation (KU 5:252). In the language of the first Critique, then, comprehension depends not only on apprehension, but also on reproduction. Admittedly, Kant does not use the term 'image' to describe the complex, holistic representation that comprehension produces; however, I believe we are warranted in conceiving of this representation along imagistic lines (see Longuenesse 1998: 273, for a similar suggestion). In the first place, the discussion of this imaginative activity maps onto his discussion of the imaginative synthesis that produces images in both the Metaphysics Lectures and first Critique. Moreover, in discussing the difficulty of comprehending very large objects that we have apprehended in the third Critique he uses the example of perceiving St. Peter's, which is the exact same example he uses in discussing images in the Metaphysics Lectures (ML 28:236). This, in turn, underlines the continued commitment Kant has to the idea that perception involves the image forming activities of the imagination.

50. Although Kant's description of apprehension as occurring "in intuition" (A97, 98) might suggest that apprehension produces not images but rather intuitions, he says that the "action I call the synthesis of apprehension is aimed directly at the intuition, which to be sure provides a manifold but can never effect this as such, and indeed as contained in one representation, without the occurrence of such a synthesis" (A99). Apprehension, then, is 'directed at' an intuition that contains a manifold. Moreover, he claims that by running through and taking together this manifold it brings it into 'one representation' and given that later he makes it clear that the result of apprehension is an image ("For the imagination is to bring the manifold of intuition into an image; 
and then ... tak[ing] it together" [das Durchlaufen der Mannigfaltigkeit und denn die Zusammennehmung desselben] (A99, translation modified). On my interpretation, this activity of running through and taking together is a successive one, i.e., one in which we gather together certain representations in the manifold as they unfold across space and over time. ${ }^{51}$ If, for example, I am at the cocktail party, instead of just being affected by the flute, my imagination can collect together the representations of it as they develop across space and over time, e.g., the initial representation of curviness, the next representation of shininess, finally the representation of the crystal pattern, etc. In short, the synthesis of apprehension is what gives me the ability to actively and successively gather together these unfolding representations.

Yet Kant suggests that apprehension alone is not sufficient for producing an image; it must be supplemented by the synthesis of reproduction:

It is, however, clear that even this apprehension of the manifold alone would bring forth no image ... were there not a subjective ground for calling back a perception, from which the mind has passed to another ... i.e., a reproductive faculty of the imagination. (A121, my emphasis)

Kant's idea is that if we were to 'always lose' representations that were contained in the manifold in the past, then we could not produce the more complex, holistic type of representation involved in an image: "if I were always to lose the preceding representations ... from my thoughts and not reproduce them when I proceed to the following ones, then no whole representation . . . could ever arise" (A102). In order, for example, to produce a representation that reflects the different aspects of the champagne flute, if by the time I am representing its curviness I have forgotten all about its glint, then I cannot produce an image of it. On Kant's view, the synthesis of reproduction is the process through which representations in the past are brought to bear on what we are representing right now. He sometimes makes this point in terms of associations: by associating the present representations with representations in the past, we can form a representation that reflects the aspects of an object we have perceived over time..$^{2}$

Ultimately, on Kant's view, the synthesis of apprehension and reproduction are 'inseparably combined' in image production: in order to form a complex, ho-

\footnotetext{
it must antecedently take up the impressions into its activity, i.e., apprehend them."), images are implicated in his discussion of apprehension in Section I.

51. Kant emphasizes the successive nature of synthesis in the Analogies of Experience, see, e.g., A182/B225, A189/B234.

52. Insofar as reproduction brings a representation that is 'absent' to bear on what is perceptually present to us, it contributes to a Kantian solution the problem of perceptual presence, discussed in footnote 22 .
} 
listic representation of an object from multiple sides and multiple points of view, we need the synthesis of apprehension to successively take up representations of that object and the synthesis of reproduction to hold onto representations of it from the past and bring them to bear on the present. 53 For example, if I am to be able to form an image of the champagne flute from different sides and points of view, I need to be able, one, to gather together the representations of it from those different sides and points of view (first its shininess, then its curve, then its crystal pattern, etc.) and, two, to bring the representations of how it appeared in the past (the shininess I noticed a minute ago) to bear on what appears presently (the crystal pattern I notice now).

Having discussed the two imaginative forms of synthesis, we should now turn to the synthesis of recognition, which is undertaken not by the imagination, but by the understanding. Kant introduces this third form of synthesis by claiming, "Without consciousness that that which we think is the very same as what we thought a moment before, all reproduction in the series of representations would be in vain" (A103, my emphasis). To illustrate why our imaginative synthesis might be in vain without this consciousness, he offers the following example,

If, in counting, I forget that the units that now hover before my senses were successively added to each other by me, then I would not cognize the generation of the multitude through this successive addition of one to the other, and consequently I would not cognize the number (A103).

Suppose, for example, I am counting out thirty-five one-dollar bills. It is only if I remain conscious that I am counting to thirty-five that I will be able to successfully count; if I lose my concentration, I will have to start over. For Kant, however, the consciousness that is involved here is not simply a matter of being awake; it is a certain type of conceptual consciousness that arises when we recognize what we intuit as falling under a particular concept. As Kant makes this point, a concept is that which provides for "the one consciousness that unifies the manifold that has been successively intuited, and then also reproduced, into one representation" (A103). On his view, the synthesis of recognition is what enables us to apply concepts to what we perceive and to thus achieve this particular type of consciousness. In the champagne flute example, the synthesis of recognition allows me to apply the concept 'champagne flute' to the various representations of the flute within the manifold that I have apprehended and reproduced, e.g., of

53. Though these forms of synthesis are inseparably combined in image production in perception, it seems that Kant allows for them to occur separately in other contexts, e.g., when we apprehend something very large, like St. Peter's, that we cannot form a holistic image of (KU 5:252) or when we reproduce representations in a dream (B278). 
its curve, glint, crystal pattern, etc., and this gives me a distinctive consciousness of what I see as falling under that concept.

Although Kant clearly states that the syntheses of apprehension and reproduction are 'inseparably combined' in image formation, it is a matter of debate whether Kant thinks that it also requires the synthesis of recognition. On the one hand, Kant's analysis of synthesis in the Metaphysical Deduction seems to point toward the idea that imaginative synthesis can occur prior to conceptual synthesis:

Synthesis in general is, as we shall subsequently see, the mere effect of the imagination, of a blind though indispensable function of the soul. . . Yet to bring this synthesis to concepts is a function that pertains to the understanding (A78/B104, my emphasis). 54

This language certainly seems to suggest that imaginative synthesis produces something that is, in turn, brought to concepts through an act of the understanding. 55 Fleshing this picture out in a bit more detail, Kant goes on to say,

The first thing that must be given to us a priori for the cognition of all objects is the manifold of pure intuition; the synthesis of this manifold by means of the imagination is the second thing, but it still does not yield cognition. The concepts that give this pure synthesis unity . . . are the third thing necessary for cognition of an object that comes before us, and they depend on the understanding. (A78-9/B104)

One way to read this passage is as articulating three different kinds of representations we can form. ${ }^{56}$ Sometimes we form representations solely through sensibility when it gives rise to a manifold of intuition in us. At other times, however, our representations are the result of our imagination synthesizing that manifold in different ways. On still other occasions, the understanding takes up what the imagination has synthesized and forms representations by unifying it under concepts. This seems to be borne out by Kant's claim that a concept "unifies the manifold that has been successively intuited, and then also reproduced,

54. As Guyer and Wood note, in Kant's copy of the A edition, he changes 'function of the soul' to 'function of the understanding', which touches on the issue of whether his view of synthesis changes after the A edition.

55. For a discussion of this point, see Allais (2009: 396).

56. This sort of view is suggested by Longuenesse (1998: 35-6). However, this passage could also be read alternatively in support of the conceptualist interpretation as indicating the three conditions that must be met in order for us to have any cognition at all. 
into one representation" (A103, my emphasis). To be sure, Kant suggests that if a concept is not brought to bear on what we imaginatively synthesize that imaginative synthesis will be 'in vain'; however, if something occurs 'in vain', it still occurs (A103). For these reasons, a number of commentators have argued that, for Kant, the imaginative syntheses of apprehension and reproduction, hence image formation can occur prior to the synthesis of recognition. 57

On the other hand, some interpreters have been led to conclude that Kant thinks the syntheses of apprehension and reproduction depend on the synthesis of recognition..$^{8}$ In the A Deduction, immediately after saying that without consciousness the synthesis of reproduction would be in vain, he goes on to say that this is because the "manifold would never constitute a whole [Ganzes], since it would lack the unity that only consciousness can obtain for it" (A103). This passage seems to suggest that the only way a manifold of intuition can be unified is through the consciousness we achieve by means of the synthesis of recognition. Now, an image is a whole representation; in which case, in order for apprehension and reproduction to be able to produce an image, it would appear they have to rely on the synthesis of recognition. Indeed, one might begin to suspect that apprehension, reproduction, and recognition are not three distinct acts, but rather three components of one act, the act through which we bring unity into the manifold of intuition in perception. 59

This interpretation appears to be corroborated by Kant's claims about synthesis in the B Deduction. To be sure, in the B Deduction Kant continues to be interested in the topic of perceptual synthesis, claiming in $\$ 26$ that one of his goals is to explain the "synthesis, through which even perception itself becomes possible" (B161); however, unlike in the A Deduction, he now appears to claim that all synthesis, even what he had previously attributed to the imagination, ultimately traces back to the understanding:

the combination (conjunctio) of a manifold in general can never come to us through the senses ...; for it is an act of the spontaneity of the power of representation, and, since one must call the latter understanding ... all combination ... is an action of the understanding, which we would designate with the general title synthesis. (B130, my emphasis) ${ }^{60}$

57. See, e.g., Young (1988), Gibbons (1994: 25-6, 30-32), Rohs (2001), Allison (2004: 187-9), and Hanna $(2005: 255,267)$. Although Young and Allison want to distance Kant's account of imaginative synthesis from image formation, Rohs acknowledges that imaginative synthesis produces images and he claims that this synthesis is pre-conceptual.

58. See, e.g., Paton (1936: Vol. 1: 271-2); Ewing (1967: 75); and Kemp Smith (1962: 245-246).

59. See, e.g., Paton (1936: Vol. 1: 376).

6o. For a discussion of this apparent shift between the A and B Deductions, see Bennett (1966: 134-138), Kitcher (1990: 158-160), Ginsborg (1997: 58-9), Allison (2001: 186-189). 
Consider, once again, Kant's example of perceiving a house:

I make the empirical intuition of a house into a perception through apprehension of its manifold ... and I as it were draw its shape in agreement with this synthetic unity of the manifold in space. This very same synthetic unity, however, if I abstract from the form of space, has its seat in the understanding, and is . . the category of quantity, with which that synthesis of apprehension, i.e., the perception, must therefore be in thoroughgoing agreement. (B162)

Although in this passage Kant seems to draw on the idea from the A Deduction that in order to perceive a house we must form an image of it by engaging in apprehension, unlike in the A Deduction, he now seems to be insisting that apprehension ultimately has its seat in the understanding and the category of quantity. As he goes on to say in the footnote to this example, "it is one and the same spontaneity that, there under the imagination and here under the name of understanding, brings combination into the manifold of intuition" (B162 footnote). If this is the case, then whether we are talking about the synthesis of apprehension or the synthesis of recognition, it would appear that we are talking about the same underlying synthetic act of the understanding. This would, in turn, mean that the synthesis involved in image formation could not occur independently from the understanding.

By my lights, we cannot properly adjudicate this issue solely on the basis of the Deduction because Kant has not yet completed his account of image formation; we need to turn our attention towards the Schematism and the important development in the theory of images we find there, which turns on Kant's claim that a schema is that "through which and in accordance with which the images [die Bilder] first become possible" (A142/B181).

\section{Images in the Schematism}

In the Schematism, Kant is concerned primarily with explaining how it is possible for us to form judgments in which we apply the categories to what we intuit through the senses ${ }^{61}$ He argues that the categories, qua pure concepts, are not 'homogeneous' [gleichartig] with our sensible intuitions and that there must be some "third thing" that is homogeneous with both that paves the way for this application (A138/B177). He identifies this third thing as a 'schema', which he

61. While my focus here is primarily on the relevance of the Schematism to Kant's theory of perception, see Matherne (2014) for my broader interpretation of the Schematism. 
describes as a special "mediating representation" produced by the imagination that is "intellectual on the one hand and sensible on the other" (A138/B177). Although Kant devotes most of his attention to the transcendental schemata associated with the categories, he does address two sensible kinds of schemata: schemata associated with pure sensible or mathematical concepts, e.g., the concept 'triangle', and schemata associated with empirical concepts, e.g., the concept 'dog' (A140-1/B179-180). It is this portion of the Schematism that shall concern us for it is in this context that Kant makes the important claim that a schema is that 'through which and in accordance with which the images first become possible'. ${ }^{62}$

To begin fleshing out this claim, it will be helpful to first consider the nature of schemata more generally. Insofar as a schema is something that mediates between a concept and an intuition, it is something that must share features of both: like an intuition, it must be a sensible representation and like a concept it must be general, i.e., capable of representing what is common to several objects. ${ }^{63}$ In order to account for the mediating nature of schemata, Kant highlights two essential features of them: first, they involve a special type of sensible yet general representation that he calls a 'monogram', and, second, they function as rules that guide imaginative synthesis. Taking these two features of schemata together, the upshot of his view is that a monogram is the representational content of a schema and this representational content functions as a rule that guides the imagination in synthesizing the manifold of intuition. As we might make this point, the monogram contained in a schema is a representation that serves as something like a stencil that guides imaginative synthesis.

With regard to the first key feature, in the Schematism Kant describes a sche-

62. Insofar as the topic of the schematism of the categories falls under the purview of the transcendental activities of the imagination I will not pursue it here; however, it is worth noting that in the Schematism, Kant says, "The schema of a pure concept of the understanding ... is something that can never be brought to an image at all, but is rather only the pure synthesis, in accord with a rule of unity according to concepts in general ... and is a transcendental product of the imagination, which concerns the determination of the inner sense in general, in accordance with conditions of its form (time) in regard to all representations" (A142/B181). As this passage indicates, rather than claiming that a transcendental schema makes an image possible, Kant suggests that it makes a particular determination of time possible. This, in turn, means that the sort of images Kant takes to be involved in perception are never images of the categories per se, but are images of more sensible concepts. I return to this issue in footnote 76 below.

63. Although some commentators (Walsh 1957/1958; Chipman 1972; and Pippin 1976) have argued that a schema is needed to solve the problem of homogeneity only in the transcendental case in which we apply the categories to intuition, given that concepts, in general, are mediate, universal representations and intuitions, in general, are immediate, singular representations, the problem of homogeneity will arise here too. As Kant makes this point in the third Critique, the understanding with its concepts and sensibility with its intuitions are "two heterogeneous elements"; hence, a schema will be needed to mediate between the two in any case in which we apply a concept to an intuition (KU 5:401). 
ma as a 'monogram' and by this term, he has in mind a holistic, but somewhat vague sensible representation like a 'sketch' [Zeichnung] or 'silhouette' [Shattenbild] (A142/B181, A570/B598). While we often think of sketches or silhouettes as physical objects, e.g., my niece's sketch hanging on my refrigerator, for Kant, there can be monograms in our head, e.g., the sketch of a face a "painter or physiognomist" has in her head (A570/B598). A schema falls in the latter category of mental sketches.

More specifically, on Kant's view, a schema is a monogram of a concept, i.e., a mental sketch that holistically represents the marks involved in a particular concept. On this point, I disagree with a number of commentators who have argued the schemata are identical to empirical concepts ${ }^{64}$ and others who argue that schemata are pre-conceptual. ${ }^{6}$ In the third Critique, Kant makes it clear that he conceives of schemata as "direct ... presentations [Darstellungen] of the concept" and he claims that they involve the 'making sensible' [Versinnlichung] of those concepts (KU 5:351-2). ${ }^{66} \mathrm{I}$ take Kant's idea to be that a concept is an intel-

64. See Bennett (1966: 151), Chipman (1972: 42), and Guyer (2006: 97). In support of this view, commentators have pointed out that Kant appears to describe both schemata and concepts as rules for the synthesis of the imagination, e.g., "The schema of the triangle ... signifies a rule of the synthesis of the imagination" and "The concept of a dog signifies a rule in accordance with which my imagination can delineate [verzeichnen] the shape [Gestalt] of a four-footed animal in general, without being restricted to any single particular shape [Gestalt] that experience offers me" (A141/ B180, translation modified). Notice, however, that he says the concept 'dog' signifies a rule that the imagination produces a schema in accordance with. By my lights, this suggests that Kant thinks of the concept 'dog' as something distinct from a schema, something the imagination produces a schema in accordance with. Admittedly, in the triangle passage, Kant says that a schema "signifies a rule for the synthesis of the imagination" (A141/B180); however, I think that he is referencing two different rules in the passages. In the dog passage, the rule he is referencing is related to a concept, whereas in the triangle passage, the rule he is referencing is related to a schema. I believe these rules are different not only because Kant draws a distinction between concepts and schemata elsewhere in the Schematism chapter and in $\$ 59$ of the third Critique (see below), but also because concepts and schemata are different types of representations: whereas a concept is a general, intellectual representation (A320/B377; JL 9:91), a schema, as I argue below, is a general, sensible representation. As such, the rules that concepts and schemata involve will be different.

65. See Pendlebury (1995: 784, 787-8), Longuenesse (1998: 115-118), and Allison (2001: 25-28), who argue that schemata must be pre-conceptual because they play a crucial role in the formation of concepts. While I think it is possible for us to develop new concepts on the basis of previously acquired schemata, I do not think schemata can ever be entirely pre-conceptual. For example, while I might be able to develop a new concept 'peony' on the basis of a previously acquired schema for flowers, this schema would not be pre-conceptual, but rather connected to the concept 'flower'. While this is a fairly high level empirical concept, it seems to me that for Kant all our empirical concepts ultimately trace back to the categories and that whatever schemata we develop, they must, in the end, be grounded in the categories. Thus, even if empirical concept formation depends on schemata, schemata are never pre-conceptual, but always connected, at the very least, to the categories.

66. This supports Heidegger's claim in Kant and the Problem of Metaphysics that, "The formation of the schema is the making-sensible of concepts" (1990: 68). 
lectual representation that involves various distinguishing marks and a schema is a monogram that represents how those various conceptual marks show up together in a sensible, holistic way. For example, the schema for the concept 'dog' will be a sensible representation, a sketch or monogram, of how its various distinguishing marks, e.g., being four-legged, furry, slobbery, an animal, etc., show up together as a whole. This schema is not, therefore, identical to the concept ' $\mathrm{dog}$ ' because it is a sensible presentation of that concept; nevertheless, it must be connected to the concept ' $\mathrm{dog}^{\prime}$ ' because that concept is what it is a monogram of.

However, if a schema is a sensible representation of a concept and a concept, on Kant's view, is general in the sense that it is a representation of what is common to several objects, then a schema will represent what is common to several objects, in which case, a schema is both a sensible and a general representation. Otherwise put, a monogram is a sensible representation that is general to the extent that it represents how the characteristic marks of a concept will show up in a holistic way and is thus applicable to various instances of that concept. My schema for the concept ' $\mathrm{dog}^{\prime}$, for example, does not just apply to my pet Brittany Spaniel; it is a sensible representation of how the various marks of the concept 'dog' show up in a holistic way, which should apply to visually dissimilar dogs, like Great Danes and Chihuahuas as well. It is for this reason that Kant insists that a schema is not to be confused with an image, i.e., a representation of a particular object that I perceive, but rather it is a general representation that can apply to different instances of a concept. As Kant makes this point with respect to triangles, "No image of a triangle would ever be adequate to the concept of it. For it would not attain the generality of the concept, which makes this valid for all triangles, right or acute, etc." (A141/B180). By contrast, the schema of a triangle will have the requisite generality that allows it to apply to all triangles. In the first place, then, on Kant's view, a schema is a monogram of a concept, which is a sensible representation that is at the same time general enough to be valid for all instances of that concept.

The second key point Kant makes about a schema is that it functions as "a rule of the synthesis of the imagination" (A141/B180, my emphasis). ${ }^{67}$ I take his basic idea to be that the monogram involved in a schema serves as something like a stencil that governs the way in which the imagination synthesizes the various representations within the manifold of intuition together. Suppose, for example, I am at a dog park. The monogram involved in my schema for dogs acts as a stencil that guides my imagination in apprehending and reproducing the repre-

67. Insofar as I take schemata to be rules that guide imaginative synthesis, I am in disagreement with Grüne (2009: 129), who denies that schemata should be understood as such rules and in agreement with Longuenesse (1998: 116-7) and Allison (2001: 26); however, I part ways with Longuenesse and Allison insofar as they treat these schematic rules as pre-conceptual. 
sentations within the manifold that belong to the dog, e.g., of its four-leggedness and slobberiness, in distinction from those that belong to other objects, like the grass or Frisbee.

Yet, according to Kant, the sort of rule that a schema functions as is of a specific sort: it is "a rule for the determination of our intuition in accordance with a certain general concept" [gemäß einem gewissen allgemeinen Begriffe] (A141/B180, my emphasis). This is a significant passage because it indicates that Kant is not thinking of schemata as pre-conceptual, but rather links them directly to concepts: they function as rules for synthesizing the manifold of intuition in light of a concept. For example, insofar as my schema for dogs functions as a rule that guides me in synthesizing the manifold of intuition in light of the concept ' dog', $^{\text {', }}$ that concept must be one that I already possess. Indeed, this view seems to follow from our reflections on schemata as monograms: if a schema is a sensible representation of a concept, then the concept will be at least implicitly involved in the imaginative synthesis that the schema guides.

It is at this point that we should return to images. Although the Deduction reveals that images are formed on the basis of (what at least goes under the name of) imaginative synthesis, viz., apprehension and reproduction, we now learn that this imaginative synthesis is, in turn, guided by schemata, i.e., rules for synthesizing the manifold of intuition in accordance with a concept. We see this idea at work in Kant's definition of a schema as "a general procedure of the imagination for providing a concept with its image" (A140/B179). It is also evident in his description of the schema for number as "a method for representing a multitude (e.g., a thousand) in an image in accordance with a certain concept" (A140/B179). This line of thought culminates in the passage where he summarizes the nature of the relationship between schemata, images, and concepts, saying that a schema is that, "through which and in accordance with which the images first become possible, but they must be connected with the concept only ever by means of the schema, which they delineate" [bezeichnen] (A141-2/B181, translation modified). ${ }^{68}$ For Kant, the images at issue 'must' be connected to a concept because they are produced through imaginative forms of synthesis that are guided by a schema, which is, in turn, connected to a concept. ${ }^{69}$ Put another way, if an image 'delineates' a schema and a schema is a monogram of a concept, then the image itself will be connected to that concept. The image I form of my

68. I translate bezeichnen as 'delineate' rather than 'designate' in order to bring out the connection between bezeichnen and zeichnen, 'to draw' or 'to sketch'. This helps emphasize the idea that a schema is a sketch of a concept. And although bezeichnen here is reminiscent of the language of abbilden ('to illustrate') he used to describe images in the Metaphysics Lectures, in this context it is clear that what is being delineated is a schema, which is, in turn, connected to a concept.

69. It is not until Section 6 that I offer a full explanation for what it means for an image to be 'connected to' or (as I say below) 'bound up with' a concept, so in this section, my language will remain somewhat vague. 
Brittany Spaniel, for example, will be connected to the concept 'dog' because that image delineates the monogram for the concept 'dog', which is involved in my schema for dogs.

Ultimately, the view of image formation that emerges in the Schematism is as follows. A schema is a monogram, i.e., a representation of a concept that is both sensible and general, and its primary function is to serve as a rule for the imaginative synthesis (apprehension and reproduction) of a manifold of intuition in accordance with that concept. The result of this schema-guided imaginative synthesis is an image. It is, thus, only in the Schematism that we get Kant's complete picture of the sort of imaginative synthesis required for image formation and, by extension, of what it means for this to be a necessary ingredient of perception. For this reason, although it is often neglected in this context, the Schematism emerges as a pivotal text for understanding Kant's framework for perception in the first Critique.

There is, however, a residual issue from our discussion of the Deduction that we need to return to. Given that this schema-guided imaginative synthesis must be conducted in accordance with a concept, it would appear that this imaginative synthesis is inseparably bound up with concepts; however, does this mean that this imaginative synthesis is also inseparably bound up with the synthesis of recognition? Or could there be some way for image formation to occur in accordance with concepts that does not require that type of synthesis?

\section{Kant's Moderate Conceptualism}

Let's call the interpretation according to which image-forming imaginative synthesis involves the synthesis of recognition 'strong conceptualism', where 'conceptualism' refers to theories of perception according to which concepts or conceptual capacities are required in order for us to perceive the world. A number of commentators have worried that by attributing strong conceptualism to Kant, we are 'over-intellectualizing' his theory of perception. $7^{\circ}$ The concern is that we are committing Kant to the view that perception involves the conscious application of concepts, a view that, as Ginsborg puts it, fails to "respect the primitive character of perception." $7^{1}$ By the 'primitive character' of perception she has in mind the features of perception that cannot be understood in conceptual terms, e.g., our ability to perceive things and form images of things we do not have concepts for. For example, suppose I lack the concept 'marjoram'. Ginsborg sug-

70. This is a phrase drawn from Allison (2004: 188) who argues that insofar as Strawson (1974) and Sellars (1978) suggest that concepts must be involved in the imaginative activity in perception, they 'over-intellectualize' Kant's account of perception.

71. Ginsborg (2008: 75). 
gests that if I am in an herb garden, I can still see marjoram and form images of it, even if I cannot "entertain thoughts" that involve that concept..$^{2}$ If Kant is a strong conceptualist about image formation, then he cannot accommodate this possibility.

In order to distance Kant's account of image formation and perception from strong conceptualism, commentators have pursued two different routes. In one vein, interpreters like Rohs have argued that Kant defends a non-conceptualist theory of perception. ${ }^{73}$ Following a line of thought we discussed above, Rohs suggests that, for Kant, perception only requires pre-conceptual acts of imaginative synthesis. Indeed, Rohs argues that this must be Kant's view because Kant conceives of pre-conceptual imaginative synthesis as a condition of conceptapplication: it supplies the understanding with the singular sensible term, i.e., the image, which we apply our concept to. 74

However, there are two worries about this non-conceptualist strategy. In the first place, it conflicts with Kant's claims in the B Deduction discussed above to the effect that all synthesis depends on the understanding. In the second place, it is in tension with his idea that synthesis depends on the categories. For example, in the A Deduction, Kant makes it clear that the categories are "a priori conditions with which [the] synthesis (of apprehension) must be in thoroughgoing accord" (A113). Generalizing this point to all imaginative synthesis, he argues,

On [the categories] is grounded, therefore, all formal unity in the synthesis of the imagination, and by means of the latter also all of its empirical use (in recognition, reproduction, association, and apprehension). (A125)

Kant makes similar claims in the B Deduction, e.g., "all synthesis, through which even perception itself becomes possible, stands under the categories" (B161, my emphasis). Relating this idea to the synthesis of apprehension, Kant claims,

72. Ginsborg (2008: 75).

73. Although Young (1988) and Allison (2004: 187-9) think images can drop out of Kant's account of imaginative synthesis, they argue that imaginative synthesis is something that occurs pre-conceptually. In a slightly different vein because she is focused on intuitions not images, Allais argues that complex perceptual representations can be the result of "processing or synthesizing that is not conceptualizing" (2009: 395). On her view, in order to perceptually represent an object with multiple properties, e.g., a tomato that is red and round, it is necessary for our "visual system to 'reassemble' or bind information from the different streams [for processing shape and color] in order to represent a single round red thing"; however, she argues that we need not conceive of this synthesis as involving concepts (2009: 394-5). In this case, the perceptual representation we form is produced on the basis not of the synthesis of recognition, but on the basis of the imaginative syntheses of apprehension and reproduction (2009: 396). For a similar argument, see Hanna (2005: 249, 267).

74. Rohs (2001: 221). 
since all possible perception depends on the synthesis of apprehension, but the latter itself, this empirical synthesis, depends on the transcendental one, thus on the categories, all possible perceptions ... a far as their combination is concerned, stand under the categories. (B164-5, my emphasis)

Insofar as these passages indicate that perceptual synthesis involves the understanding and the categories, they undermine the non-conceptualist account of synthesis.

Meanwhile Ginsborg, who is sensitive both to these passages from the Deduction and the worry about over-intellectualizing Kant's account of perception, has adopted a different strategy, which we could call 'weak conceptualism' (2008: Section I). According to Ginsborg, the above passages from the Deduction reveal that the understanding must be involved in perceptual synthesis; however, she argues that this does not commit Kant to the stronger view that concepts must be involved in perceptual synthesis. On her interpretation, Kant allows for imaginative synthesis to be guided by the understanding without being guided by any "antecedently grasped concept" (2008: 71) She claims that this occurs when the imaginative synthesis involved in image formation is guided by the "consciousness of normativity" that the understanding provides, i.e., an awareness that one is synthesizing 'appropriately' or as she 'ought' (2008: 71, 73). If, for example, I do not possess the concept 'marjoram', the understanding can still be involved in synthesis if I sense that I am synthesizing the manifold together in the way that I 'ought'. It is on the basis of this normativity-guided synthesis that Ginsborg suggests images are formed.75

There are, however, two ways in which weak conceptualism conflicts with Kant's treatment of perception. To begin, in the passages from the Deduction cited above, Kant does not just say that perceptual synthesis depends on the understanding; he says it depends on the categories. Given that these are concepts, it would seem that, at the very least, the categories must be involved in the synthesis through which images are formed..$^{76}$ Moreover, weak conceptualism is

75. Longuenesse (1998: 116-120) offers a different take on what this pre-conceptual normative guidance amounts to, arguing that perception involves synthesis that is guided by schemata, which are pre-conceptual rules and which, in turn, serve as the basis for empirical concept formation. Although I am sympathetic to the idea that perception involves schema-guided synthesis, for reasons discussed above, my interpretation diverges from Longuenesse's because I have a more conceptualist interpretation of schemata than she does.

76. Griffith (2012: 2, 6-7) and Williams (2012) argue that perceptual synthesis only requires transcendental concepts, not empirical concepts. While Kant certainly emphasizes the role the categories play in synthesis in the Deduction, I believe that his views in the third Critique indicate that he would think empirical concepts must be involved as well. As Allison (2001: 20) has emphasized, in the third Critique Kant argues that the categories operate at a very abstract level, determining "nature in general" in accordance with abstract laws, e.g., "All alteration has its cause" (KU 5:183). However, he claims that the "objects of empirical cognition" need to be further determined by 
in tension with Kant's analysis of image formation in the Schematism. For in the Schematism Kant does not just suggest that a schema enables us to synthesize a manifold of intuition in accordance with the understanding, but in accordance with $a$ concept. This is why he insists on the connection between images, schemata, and concepts: images are made possible by schemata, which connect them to particular concepts.

Though this might seem to point once again towards Kant as a strong conceptualist, in what remains, I would like to suggest that he is better read as holding a moderate version of conceptualism, according to which image formation is guided by concepts, though not by the synthesis of recognition. Recall that, for Kant, the synthesis of the recognition is accompanied by a distinctive type of conceptual consciousness: we are aware of what we perceive as falling under a particular concept.77 I take this to imply that in the synthesis of recognition, we must be consciously or reflectively aware of what we perceive in conceptual terms, e.g., being aware of this object as falling under the concept 'champagne flute'. Yet this still leaves room for the possibility that our concepts could be guiding imaginative activity on a more sub-conscious, unreflective level. After all, Kant tends to emphasize the less reflective nature of the imagination, saying it is a "blind though indispensable function of the soul ... of which we are seldom ever conscious" (A78/B103). Or as he says of the schematism of the imagination, it is a "hidden art in the depths of the human soul, whose true operations we can divine from nature and lay unveiled before our eyes only with difficulty" (A141)

more specific empirical laws (KU 5:183). For example, although the category of cause indicates that an object will have some cause or other, this object can still be caused "in infinitely many ways," so we need an empirical causal concept to tell us which sort of cause is responsible for this object (KU 5:183). Summarizing this point, Kant claims, "The understanding is of course in possession a priori of universal laws of nature, without which nature could not be an object of experience at all; but still it requires in addition a certain order in nature in its particular rules, which can only be known to it empirically" (KU 5:184, my emphasis). I take this passage to indicate that our concrete perceptual encounters with the world do not just involve the categories, but empirical concepts as well. On my interpretation, this has implications for Kant's account of perception and image formation: we do not just form images on the basis of the categories. In fact, Kant claims that, "The schema of a pure concept of the understanding ... is something that can never be brought to an image at all" (A142/B181). But if the categories cannot be brought to an image and an image is required for perception, it would seem we must rely on empirical concepts in image formation.

77. I emphasize the idea that this is a distinctive sort of conceptual consciousness because Kant is committed to the view that perception involves what he calls "empirical consciousness": "by the synthesis of apprehension I understand the composition of the manifold in an empirical intuition, through which perception, i.e., empirical consciousness of it (as appearance), becomes possible" (B160) and "Perception is empirical consciousness" (B207). However, I take this kind of empirical consciousness to be distinct from the specific sort of conceptual consciousness that we have in the synthesis of recognition. On my interpretation of Kant's view, we can be empirically conscious of something we perceive without being conscious of it as falling under a certain concept. 
B180). My proposal is that, for Kant, imaginative synthesis is guided by concepts in a more unreflective way, in a way that we are not yet conscious of. $7^{8}$

In order to spell out this view, I want to draw on a distinction, emphasized by Young (1988: 153), that Kant uses in the Jäsche Logic and the Groundwork between something occurring in accordance with a rule and in accordance with a representation of a rule (see Gr 4:412, JL 9:11). According to Kant, the former case occurs when we are 'unconscious' of a rule: "The exercise of our powers also takes place according to certain rules that we follow, unconscious of them at first, until we gradually arrive at cognition of them" (JL 9:11). It is only once we become conscious of the rule that we can act in accordance with a representation of it. Now, in the Logic, Kant is clear that he is thinking of the understanding both as the "source of rules" (JL 9:11) and as the "faculty of concepts" (JL 9:36) in which case, it stands to reason that the rules he has in mind here are concepts.79 This means that the distinction Kant is drawing is between something occurring unconsciously in accordance with a concept and something occurring consciously in accordance with a representation of a concept. ${ }^{80}$

Turning back to the first Critique, I would like to suggest that schemagoverned synthesis is done unconsciously in accordance with a concept and does not require the sort of conscious representation of a concept involved in the synthesis of recognition..$^{81}$ That schema-guided synthesis occurs in accordance

78. Insofar as I think concepts can guide synthesis in an unreflective way, I am sympathetic to Grüne's claim that synthesis can be guided by 'obscure concepts' (2009: Ch. 4); however, my account differs from Grüne's on several points. First, Grüne identifies intuitions, which she defines as complex representations formed on the basis of synthesis, with images (see, e.g., 2009: 53, 229); on my interpretation, by contrast, there is a distinction between intuitions in a narrow sense, which are formed through sensibility, and images, which are formed through synthesis. I take Kant's view to be that intuitions are formed on the basis of sensibility alone and do not depend on the sort of synthesis Kant describes in the Deduction. This is not to deny that within an intuition, the manifold of representations are connected together; rather it seems to me that this is accomplished through the 'synopsis', which Kant ascribes to sense, and which does not, as Grüne would have it, depend on synthesis. Furthermore, although I agree with Grüne that perception involves the formation of complex sensible representations on the basis of synthesis that is guided by concepts in an unreflective way, I do not agree with Grüne's claim that this occurs through the synthesis of recognition (see Grüne 2009: Chs. 3.3, 4). While Grüne wants to allow for the synthesis of recognition to proceed in an unreflective way, on my interpretation, the synthesis of recognition necessarily involves consciousness in a way that the concept-guided imaginative synthesis does not.

79. On this point, I differ from Young, who argues that the unconscious rules are preconceptual.

80. I believe that this can map onto Grüne's (2009: Ch. 1) analysis of concepts as follows: the former 'unconscious' concepts would align with 'obscure' concepts, whereas the 'conscious' concepts would align with 'clear' and 'distinct' concepts.

81. See Landy (2015: 144-150) for the argument that what Kant means by imaginative synthesis occurring 'in accordance with a concept' is that it instantiates or models rules, but does 
with a concept follows from Kant's definition of a schema as a rule for synthesizing a manifold in accordance with a concept. And, on my view, insofar as it involves concepts, we can accommodate Kant's claims in the B Deduction that all imaginative synthesis traces back to the understanding. Recall, however, that Kant describes schematism as a 'hidden art in the depths of the human soul'. I take this to indicate that our schematizing activities are ones that occur on a more unconscious level. I can engage in schema-guided imaginative synthesis and form an image without having reflectively brought a concept to bear on what I see. For example, it is possible for me to form an image of my dog, i.e., form a complex, holistic representation of her as she darts hither and thither across the park, without being reflectively aware of her as falling under the concept 'dog'. Although I can only form the image by imaginatively synthesizing the manifold in accordance with the concept ' $\mathrm{dog}^{\prime}$, it would require a further act to consciously apply the concept 'dog' to what I see. If this latter act occurs, then I bring a conscious unity to the manifold: I would become aware of what I see as falling under the concept dog. However, prior to this act, the image of my dog is unified insofar as it is a holistic representation of her from multiple sides and points of view. ${ }^{82}$ This latter unity is what the schema provides when it guides me in unconsciously synthesizing the manifold in accordance with the concept ' $\mathrm{dog}^{\prime}$. As we might make the point, the image is something that is conceptually structured: it reflects how in this instance the various distinguishing marks of a concept show up in a sensible, holistic way. Yet we are not conscious of what we see as conceptually structured, as falling under that concept. Kant's conceptualism is thus moderate in the sense that rather than require conscious concept application for image formation, he allows for us to form images on the basis of synthesis that is unconsciously guided by a concept.

The sort of conceptualism I attribute to Kant is also moderate in the sense that it is not so completely thoroughgoing as to ignore a layer of something preconceptual in our perceptual relation to the world. I have urged that Kant is a conceptualist with regard to one particular feature of perception, viz., images.

not obey them. Unlike when we obey a rule, Landy argues that instantiating a rule is something that can happen 'blindly'. My view, however, differs from Landy's with respect to our analysis of intuition: whereas on his view, intuitions are conceptually structured representations that are produced through the syntheses of apprehension, reproduction, and recognition, I endorse a non-conceptualist reading of intuitions. My view also differs from Landy's with regard to the relationship between the imagination and the synthesis of recognition: whereas I maintain that the imagination can produce the sort of holistic representations involved in images without relying on the synthesis of recognition and maintain instead that it relies on the synthesis of apprehension and reproduction occurring in accordance with a concept, Landy maintains that imaginative synthesis cannot produce the relevant complex representation without the synthesis of recognition being involved (2015: 138-9).

82. For a recent discussion of the different kinds of 'unity' a representation can have for Kant, see McLear (2015). 
However, my interpretation of Kant's framework for perception does not commit him to the view that our perceptual relation to the world is something shaped by concepts 'all the way out'. ${ }^{83}$ Rather, on my reading, Kant acknowledges that our imaginative capacity for image formation is parasitic on the non-conceptual deliveries of sensibility, i.e., sensations and intuitions in the narrow sense. ${ }^{84} \mathrm{As}$ I emphasized above, I believe that this line of thought emerges in the Transcendental Deduction. In the first place, Kant claims that the manifold of intuition is something that is provided solely be sensibility as is evident in passages like the following: "I therefore ascribe a synopsis to sense, because it contains a manifold in its intuition" (A97, my emphasis) and "The manifold of representations can be given in an intuition that is merely sensible, i.e., nothing but receptivity" (B129, my emphasis). He then goes on to argue that synthesis is something that takes up this given manifold: in the A Deduction, for example, he describes the synthesis of the imagination as "the synthesis of this manifold through the imagination" (A94, my emphasis) and in the B Deduction, he says, "by the synthesis of apprehension I understand the composition of the manifold" (B160, my emphasis). Indeed, this point is made even more clearly with respect to images, when he claims that in synthesis "the imagination is to bring the manifold of intuition into an image" (A120, my emphasis). Altogether, this suggests that, for Kant, the synthesis of the imagination required for perception is something that acts on a pre-conceptual manifold of intuition given to us through sensibility.

In the end, what I take this evidence to indicate is that the non-conceptualist is right to claim that, for Kant, there is something about our perceptual relation to the world that resists conceptualism: on his view, intuition contains a manifold of intuition that is independent of both concept-guided imaginative synthesis, as well as the conceptual synthesis of recognition. ${ }^{85}$ Nevertheless, now

83. This phrase is borrowed from McDowell (2007: 338).

84. Contrary to Ginsborg who takes images to be the 'primitive', i.e., pre-conceptual component of perception, on my view, it is intuitions that play this role.

85. One argument in favor of non-conceptualism that I have not yet addressed concerns the continuity between animal and human perception. McLear (2011), for one, has argued that Kant's remarks about animals indicate that he attributes to animals perceptual awareness of objects, which does not depend on conceptualization. While I cannot go into all the details of Kant's account of animal perception here, there are three claims that he makes in this context that seem relevant to our discussion: first, that animals have senses and a reproductive imagination (e.g., ML 28:277), second, that they have representations (VL 28:846; JL 9:65; KU 5:464), and, third, that they can both see objects, e.g., an ox can see his stall and the door of his stall, and are capable of distinguishing between perceptual objects, e.g., "The dog differentiates the roast from the loaf" (FS 2:59-60). These claims, in turn, raise the following question: if animals have a capacity for sensibility and the imagination and if representations are involved in their perception of objects, then shouldn't we think that it is possible to have objective perception and to form images without relying on conceptual capacities? Although the textual evidence indicates that animals perceive objects in some sense, I believe that their perception is specifically different from that of human beings. In the first place, Kant insists that human beings and animals are different species (e.g., ML 28:276): this 
that we have restored images, image formation, and the imagination to Kant's theory of perception, we find that he is committed to being a conceptualist with respect to a necessary ingredient of perception, viz., our ability to form holistic representations of objects as they appear to us from multiple sides and multiple points of view. This is a subtle, more mitigated form of conceptualism than is often attributed to Kant; however, this promising view emerges only if we take into account the centrality of the imagination, alongside sensibility and understanding, in Kant's framework for perception.

\section{Acknowledgments}

I would like to thank Lucy Allais, Matt Bateman, Dai Heide, Paul Hurley, Pierre Keller, Amy Kind, James Kreines, Colin McLear, David Landy, Lisa Shabel, Lisa Shapiro, Julie Tannenbaum, Clinton Tolley, Peter Thielke, Eric Watkins, three anonymous referees, and audiences at Simon Fraser in 2014, the Pacific APA in 2014, and the NAKS session on the imagination at the Pacific APA in 2015 for invaluable feedback on this paper.

is due, in part, to the fact that animals lack an understanding and self-consciousness (ML 28:276) and, in part, to the fact that animals are wholly passive, whereas human beings have spontaneity (ML 28:249, 29:202). Given this specific difference, Kant claims that "gradation from animals to man does not occur" (DWL 24:702). I believe that this has implications for how Kant conceives of the relationship between human and animal perception. Indeed, when we look at Kant's description of animal versus human perception, a very different picture emerges in each case. Kant claims that the "guiding thread" of animal perception is instinct (ML 29:949, see also ML 28:594, 28:690). Consider the dog's ability to distinguish between the loaf and meat: "the sensations caused by the roast are a ground of desire in the dog which differs from the desire caused by the loaf, and according to the natural connection which exists between its drives and its representations" (FS 2:60). Here the dog's perception and the use of its senses and reproductive imagination are passively driven by instinct and desire. This is quite different from the picture of image formation in human perception that Kant offers us in the first Critique. In our case, perception and image formation depends on imaginative synthesis (at both the reproductive and productive level, which we did not consider in this paper) and since Kant maintains that synthesis involves "the spontaneity of our thought," human perception involves spontaneity (A77/B102). Thus the entire spontaneous framework for the exercise of our imagination in human perception is different from the passive, instinctual framework of animal perception. Indeed, Kant himself even claims that it would be better if we could use a different name to describe the reproductive imagination in the animal and human case: "All three of these cognitive faculties [i.e., imagination, imagining, and anticipation, which have their source in the reproductive imagination] can be accompanied by apperception or not. When they are, then they belong only to human beings, when not-then animals also have them. We ought, therefore, to have two different name for these, but for this [faculty] there is only one, namely, the reproductive power of imagination" (ML 29:884). So even if animals are capable of perceiving objects by relying on their reproductive imaginations, this activity is importantly different from the imaginative activity of image formation that he takes to be required for human perception; in which case, if he does offer a non-conceptualist account of animal perception, then this need not preclude him from offering a conceptualist account of human perception. 


\section{References}

Abela, Paul (2002). Kant's Empirical Realism. Oxford University Press. http://dx.doi. org/10.1093/acprof:oso/9780199242740.001.0001

Allais, Lucy (2009). Kant, Non-Conceptual Content, and the Representation of Space. Journal of the History of Philosophy, 47(3):383-413. http://dx.doi.org/10.1353/hph.0.0134

Allais, Lucy (2015). Synthesis and Binding. Manuscript in preparation.

Allison, Henry (2001). Kant's Theory of Taste. Cambridge University Press. http://dx.doi. org/10.1017/cbo9780511612671

Allison, Henry (2004). Kant's Transcendental Idealism. Yale University Press.

Armstrong, David (1968). A Materialist Theory of the Mind. Routledge \& Kegan Paul.

Bennett, Jonathan (1966). Kant's Analytic. Cambridge University Press. http://dx.doi. org/10.1017/cbo9780511554506

Chipman, Lauchlan (1972). Kant's Categories and Their Schematism. Kant-Studien, 63(1): 36-5o. http://dx.doi.org/10.1515/kant.1972.63.1-4.36

Dennett, Daniel (1979). Two Approaches to Mental Images. In Ned Block (Ed.), Imagery (87-107). The MIT Press.

Dennett, Daniel (1986). Content and Consciousness. Routledge \& Kegan Paul.

Descartes, René (1972). Treatise on Man. T.S. Hall (Trans.). Harvard University Press.

Engstrom, Stephen (2006). Understanding and Sensibility. Inquiry, 49(1): 2-25. http:// dx.doi.org/10.1080/00201740500497225

Ewing, A.C. (1967). A Short Commentary on Kant's Critique of Pure Reason. University of Chicago Press.

Gendler, Tamar (2013). Imagination. In Edward N. Zalta (Ed.), The Stanford Encyclopedia of Philosophy (Fall 2013 Edition).

Gibbons, Sarah (1994). Kant's Theory of Imagination. Oxford University Press.

Ginsborg, Hannah (1997). Lawfulness without a Law: Kant on the Free Play of Imagination and Understanding. Philosophical Topics, 25(1): 37-81. http://dx.doi.org/10.5840/ philtopics199725119

Ginsborg, Hannah (2008). Was Kant a Nonconceptualist? Philosophical Studies, 137(1): 6577. http://dx.doi.org/10.1007/s11098-007-9163-3

Gomes, Anil (2014). Kant on Perception: Naive Realism, Non-Conceptualism, and the BDeduction. Philosophical Quarterly, 64(254): 1-19. http://dx.doi.org/10.1093/pq/pqt019

Goy, Ina (2012). Kant on Formative Power. Lebenswelt, 2: 26-49.

Griffith, Aaron (2012). Perception and the Categories. European Journal of Philosophy, 2o(2): 193-222. http://dx.doi.org/10.1111/j.1468-0378.2010.00404.x

Grüne, Stefanie (2009). Blinde Anschauung. Zur Rolle von Begriffen in Kants Theorie sinnlicher Synthesis. Klostermann.

Grüne, Stefanie (2011). Is There a Gap in Kant's B Deduction? International Journal of Philosophical Studies, 19(3): 465-49o. http://dx.doi.org/10.1080/09672559.2011.595196

Guyer, Paul (2006). Kant. Routledge.

Hanna, Robert (2005). Kant and Nonconceptual Content. European Journal of Philosophy, 13(2): 247-290. http://dx.doi.org/10.1111/j.0966-8373.2005.00229.x

Hanna, Robert (2006). Kant, Science, and Human Nature. Oxford University Press. http:// dx.doi.org/10.1093/acprof:oso/9780199285549.001.0001

Hanna, Robert (2008). Kantian Non-Conceptualism. Philosophical Studies, 137(1): 41-64. http://dx.doi.org/10.1007/s11098-007-9166-0

Hanna, Robert (2011). Beyond the Myth of the Myth: A Kantian Theory of Non-Conceptual 
Content. International Journal of Philosophical Studies, 19(3): 323-398. http://dx.doi.org/ 10.1080/09672559.2011.595187

Heidegger, Martin (1990). Kant and the Problem of Metaphysics (5th ed.). Richard Taft (Trans.). Indiana University Press.

Husserl, Edmund (1982). Ideas Pertaining to a Pure Phenomenology and to a Phenomenological Philosophy. F. Kersten (Trans.). Nijhoff.

Kant, Immanuel (1998). Critique of Pure Reason. (Paul Guyer and Allen Wood Eds. and Trans.). Cambridge University Press. http://dx.doi.org/10.1017/cbo9780511804649

Kant, Immanuel (2012). Groundwork to the Metaphysics of Morals. (Mary Gregor and Jens Timmermann Eds. and Trans.). Cambridge University Press.

Kant, Immanuel (2002). Critique of the Power of Judgment. (Paul Guyer and Eric Matthews Eds. and Trans.). Cambridge University Press.

Kant, Immanuel (2006). Anthropology from a Pragmatic Point of View. (Robert Louden Trans.). Cambridge University Press.

Kant, Immanuel (1992). The False Subtlety of the Four Syllogistic Figures. In David Walford (Ed. and Trans.), Theoretical Philosophy: 1755-1770 (85-106). Cambridge University Press.

Kant, Immanuel (1992). Dohna-Wundlacken Logic. In J. Michael Young (Ed. and Trans.), Lectures on Logic (431-516). Cambridge University Press.

Kant, Immanuel (1992). Jäsche Logic. In J. Michael Young (Ed. and Trans.), Lectures on Logic (521-640). Cambridge University Press.

Kant, Immanuel (1997). Lectures on Metaphysics. Karl Ameriks and Steve Naragon (Eds. and Trans.). Cambridge University Press. http://dx.doi.org/10.1017/cbo9781107049505

Kant, Immanuel (2005). Notes and Fragments. Curtis Bowman, Paul Guyer, and Fred Rauscher (Eds. and Trans.). Cambridge University Press. http://dx.doi.org/10.1017/ cbo9780511498756

Kant, Immanuel (1902). Kants gesammelte Schriften. Deutschen [formerly, Königlichen Preussichen] Akademie der Wissenschaften (Eds.). Walter de Gruyter.

Kemp Smith, Norman (1962). A Commentary to Kant's "Critique of Pure Reason" (2nd ed.). Humanities Press.

Kind, Amy (2001). Putting the Image Back in Imagination. Philosophy and Phenomenological Research, 62(1): 85-110.

Kind, Amy (in press). Imaginative Presence. In Fabian Dorsch, Martine Nide-Rumelin, and Fiona Macpherson (Eds.), Phenomenal Presence. Oxford University Press. http:// dx.doi.org/10.1111/j.1933-1592.2001.tb00042.x

Kitcher, Patricia (1990). Kant's Transcendental Psychology. Oxford University Press.

Land, Thomas (2011). Kantian Conceptualism. In Günther Abel and James Conant (Eds). Rethinking Epistemology (197-239). de Gruyter. http://dx.doi. org/10.1515/9783110253573.197

Landy, David (2015). Kant's Inferentialism: The Case Against Hume. Routledge.

Longuenesse, Béatrice (1998). Kant and the Capacity to Judge. Charles T. Wolfe (Trans.). Princeton University Press.

Makkreel, Rudolph (1990). Imagination and Interpretation in Kant. University of Chicago Press.

Matherne, Samantha (2014). Kant and the Art of Schematism. Kantian Review, 19(2): 181205. http://dx.doi.org/10.1017/S1369415414000016

Matherne, Samantha (2016). Kant's Theory of the Imagination. In Amy Kind (Ed.), The Routledge Handbook of Philosophy of Imagination. Routledge. 
McDowell, John (1994). Mind and World. Harvard University Press.

McDowell, John (2007). What Myth? Inquiry, 50(4): 338-351. http://dx.doi. org/10.1080/00201740701489211

McDowell, John (2009). Having the World in View. Harvard University Press.

McLear, Colin (2011). Kant on Animal Consciousness. Philosophers' Imprint, 11(15): 1-16.

McLear, Colin (2015). Two Kinds of Unity in the Critique of Pure Reason. Journal of the History of Philosophy, 53(1): 79-110. http://dx.doi.org/10.1353/hph.2015.0011

McLear, Colin (in press). Kant on Perceptual Content. Mind.

Noë, Alva (2004). Action in Perception. The MIT Press.

O'Regan, J.Kevin and Alva Noë (2001). What it is Like to See: A Sensorimotor Theory of Visual Experience. Synthèse, 129(1): 79-103. http://dx.doi.org/10.1023/A:1012699224677

Paton, H.J. Kant's Metaphysics of Experience (Vols. 1-2). New York: Macmillan (1936).

Pendlebury, Michael (1995). Making Sense of Kant's Schematism. Philosophy and Phenomenological Research, 55(4): 777-797. http://dx.doi.org/10.2307/2108332

Pippin, Robert B. (1976). Schematism and Empirical Concepts. Kant-Studien, 67(1-4): 156-171. http://dx.doi.org/10.1515/kant.1976.67.1-4.156

Rohs, Peter (2001). Bezieht sich nach Kant die Anschauung unmittelbar auf Gegenstände? In Proceedings of the $9^{\text {th }}$ International Kant-Congress (Vol. II, 214-228). de Gruyter.

Scruton, Roger (1974). Art and Imagination. Methuen \& Co. http://dx.doi. org/10.1515/9783110874129.584

Sedgwick, Sally (1997). McDowell's Hegelianism. European Journal of Philosophy, 5(1): 2138. http://dx.doi.org/10.1111/1468-0378.00025

Sellars, Wilfrid (1967). Science and Metaphysics. Ridgeview Publishing Company.

Sellars, Wilfrid (1978). The Role of the Imagination in Kant's Theory of Experience. In Henry W. Johnstone Jr. (Ed.), Categories: A Colloquium (231-245). Pennsylvania State University.

Shorter, J.M. (1952). Imagination. Mind, 61(244): 528-542. http://dx.doi.org/10.1093/ mind/LXI.244.528

Strawson, P.F. (1974). Imagination and Perception. In Freedom and Resentment and Other Essays (50-72). Harper \& Row Publishers.

Thomas, Alan (2010). Perceptual Presence and the Productive Imagination. Philosophical Topics, 37(1): 153-174. http://dx.doi.org/10.5840/philtopics200937121

Tolley, Clinton (2013). The Non-Conceptuality of the Content of Intuitions: A New Approach. Kantian Review, 18(1): 107-36. http://dx.doi.org/10.1017/S1369415412000313

Tolley, Clinton (2015). Transcendental Idealism as a Theory of Intentionality. Manuscript in preparation.

Walsh, W.H. (1957/1958). Schematism. Kant-Studien, 49(1-4): 95-106.

Walton, Kendall (1990). Mimesis as Make Believe. Harvard University Press.

Wenzel, Christoph (2005). Spielen nach Kant die Kategorien schon bei der Wahrnehmung eine Rolle? Kant-Studien, 96(4): 407-426. http://dx.doi.org/10.1515/kant.2005.96.4.407

White, Alan (1990). The Language of Imagination. Basil Blackwell.

Williams, Jessica (2012). How Conceptually Guided are Kantian Intuitions? History of Philosophy Quarterly, 29(1): 58-78.

Young, J. Michael (1988). Construction, Schematism, and Imagination. Topoi, 3(2): 123131. http://dx.doi.org/10.1007/BF00149784

Young, J. Michael (1988). Kant's View of Imagination. Kant-Studien, 79(2): 140-64. http:// dx.doi.org/10.1515/kant.1988.79.1-4.140 